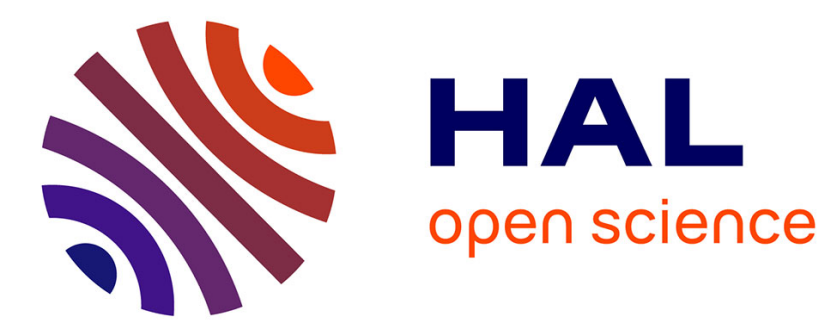

\title{
TransCom satellite intercomparison experiment: Construction of a bias corrected atmospheric CO 2 climatology
}

Ryu Saito, Sander Houweling, Prabir Patra, Dmitry Belikov, Ravindra Lokupitiya, Yosuke Niwa, Frederic Chevallier, Tazu Saeki, Shamil Maksyutov

\section{To cite this version:}

Ryu Saito, Sander Houweling, Prabir Patra, Dmitry Belikov, Ravindra Lokupitiya, et al.. TransCom satellite intercomparison experiment: Construction of a bias corrected atmospheric CO 2 climatology. Journal of Geophysical Research: Atmospheres, 2011, 116 (D21), 10.1029/2011JD016033 . hal02957289

\section{HAL Id: hal-02957289 \\ https://hal.science/hal-02957289}

Submitted on 8 Oct 2020

HAL is a multi-disciplinary open access archive for the deposit and dissemination of scientific research documents, whether they are published or not. The documents may come from teaching and research institutions in France or abroad, or from public or private research centers.
L'archive ouverte pluridisciplinaire HAL, est destinée au dépôt et à la diffusion de documents scientifiques de niveau recherche, publiés ou non, émanant des établissements d'enseignement et de recherche français ou étrangers, des laboratoires publics ou privés. 


\title{
TransCom satellite intercomparison experiment: Construction of a bias corrected atmospheric $\mathrm{CO}_{2}$ climatology
}

\author{
Ryu Saito, ${ }^{1,2}$ Sander Houweling, ${ }^{3,4}$ Prabir K. Patra, ${ }^{2}$ Dmitry Belikov, ${ }^{1}$ \\ Ravindra Lokupitiya, ${ }^{5}$ Yosuke Niwa, ${ }^{6,7}$ Frédéric Chevallier, ${ }^{8}$ Tazu Saeki, ${ }^{1}$ \\ and Shamil Maksyutov ${ }^{1}$
}

Received 29 March 2011; revised 6 August 2011; accepted 17 September 2011; published 15 November 2011.

[1] A model-based three-dimensional (3-D) climatology of atmospheric $\mathrm{CO}_{2}$ concentrations has been constructed for the analysis of satellite observations, as a priori information in retrieval calculations, and for preliminary evaluation of remote sensing products. The locations of ground-based instruments and the coverage of aircraft in situ measurements are limited and do not represent the full atmospheric column, which is a primary requirement for the validation of satellite data. To address this problem, we have developed a method for constructing a 3-D $\mathrm{CO}_{2}$ climatology from the surface up to approximately $30 \mathrm{~km}$ by combining information from in situ measurements and several transport models. The model-simulated $\mathrm{CO}_{2}$ concentrations have been generated in the framework of the TransCom satellite experiment. The spatial and temporal biases of the transport-model-derived data set have been corrected using in situ $\mathrm{CO}_{2}$ measurements in the troposphere and in situ profiles of the mean age of air in the stratosphere. The constructed multimodel mean $\mathrm{CO}_{2}$ climatology represents the seasonal cycle and the inter-hemispheric gradient better than each transport model. Our approach performs well near the surface and in regions where the observational network is relatively dense. The column-mean $\mathrm{CO}_{2}$ of the constructed climatology was reduced by $\sim 1 \mathrm{ppm}$ from that of a single transport models, consistent with model validation against measurements of the $\mathrm{CO}_{2}$ total column.

Citation: Saito, R., S. Houweling, P. K. Patra, D. Belikov, R. Lokupitiya, Y. Niwa, F. Chevallier, T. Saeki, and S. Maksyutov (2011), TransCom satellite intercomparison experiment: Construction of a bias corrected atmospheric $\mathrm{CO}_{2}$ climatology,

J. Geophys. Res., 116, D21120, doi:10.1029/2011JD016033.

\section{Introduction}

[2] Satellite measurements of the atmospheric $\mathrm{CO}_{2}$ abundance are expected to improve our understanding of $\mathrm{CO}_{2}$ surface fluxes [Rayner and O'Brien, 2001; Patra et al., 2003; Houweling et al., 2004; Chevallier et al., 2007]. The global coverage of satellite measurements provides a wealth of information supporting the estimation of atmospheric $\mathrm{CO}_{2}$ sources and sinks using inverse modeling techniques such as data assimilation [Chevallier et al., 2005; Baker et al., 2006;

\footnotetext{
${ }^{1}$ Center for Global Environmental Research, National Institute for Environmental Studies, Tsukuba, Japan.

${ }^{2}$ Research Institute for Global Change, JAMSTEC, Yokohama, Japan.

${ }^{3}$ SRON Netherlands Institute for Space Research, Utrecht, Netherlands.

${ }^{4}$ Institute for Marine and Atmospheric Research, Utrecht, Netherlands.

${ }^{5}$ Department of Atmospheric Science, Colorado State University, Fort Collins, Colorado, USA.

${ }^{6}$ Atmosphere and Ocean Research Institute, University of Tokyo, Kashiwa, Japan.

${ }^{7}$ Now at Meteorological Research Institute, Tsukuba, Japan.

${ }^{8}$ Laboratoire des Sciences du Climat et de l'Environnement, CEACNRS-UVSQ/IPSL, Gif-sur-Yvette, France.
}

Copyright 2011 by the American Geophysical Union. 0148-0227/11/2011JD016033
Chevallier et al., 2009; Engelen et al., 2009] or the ensemble Kalman filter [Peters et al., 2007; Feng et al., 2009], particularly for the regions where in situ measurements of $\mathrm{CO}_{2}$ are sparse [e.g., Patra et al., 2003]. Recently column mean $\mathrm{CO}_{2}$ concentrations $\left(\mathrm{X}_{\mathrm{CO} 2}\right)$ have been retrieved from SCanning Imaging Absorption spectroMeter for Atmospheric CartograpHY (SCIAMACHY), Atmospheric Infrared Sounder (AIRS) and Greenhouse gases Observing SATellite (GOSAT) instruments [Jiang et al., 2010; Schneising et al., 2011; Yoshida et al., 2011]. Validation of satellite-retrieved $\mathrm{X}_{\mathrm{CO} 2}$ requires simultaneous ground-based measurements of $\mathrm{CO}_{2}$ concentration profiles, which is limited, however, by the number of available measurement sites [Araki et al., 2010; Wunch et al., 2011]. In addition to the use of local $\mathrm{CO}_{2}$ concentrations, validation of preliminary satellite data is needed at larger spatial scales. For this purpose, fluxes optimized by an inverse model should be used in forward transport models to simulate 3-D atmospheric $\mathrm{CO}_{2}$ distribution appropriately. However, the availability of such flux estimates commonly lags behind the collection of new data by several months. In addition, the quality of the model-derived estimates is compromised by transport model errors, which are difficult to identify using a single forward 
model only. The alternative methodology presented in this study has been developed with the aim to reduce these limitations, and facilitate the initial verification of new satellite measurements.

[3] Transport models are becoming increasingly sophisticated with the availability of larger amounts of observation data and improved parameterizations of physical processes. Within the atmospheric tracer transport inter-comparison project (TransCom), transport model uncertainties are quantified by coordinated model inter-comparison experiments addressing variability at various scales, including diurnal, synoptic, seasonal and interannual variability [Gurney et al., 2004; Law et al., 2008; Patra et al., 2008]. The TransCom continuous experiment assessed the performance of state-ofthe-art atmospheric $\mathrm{CO}_{2}$ transport models by comparing forward simulations with high frequency in situ observations. The TransCom satellite experiment (S. Maksyutov et al., The TransCom satellite experimental protocol, 2007, available from the authors; hereinafter referred to as Maksyutov et al., unpublished report, 2007), which is used in this study, was designed to study the spatial and temporal variability of atmospheric $\mathrm{CO}_{2}$ as measured by satellites. Using simulated temporal variations of $\mathrm{CO}_{2}$ by one global transport model, a priori covariance of vertical profiles has already been constructed [Eguchi et al., 2010], which is being used in the GOSAT retrieval algorithm at NIES [Yoshida et al., 2011].

[4] However, these simulations suffer from a temporally and spatially varying seasonal bias in the simulated $\mathrm{CO}_{2}$ concentrations that arises from errors in the transport models and specified surface fluxes. Here, results from the experiment are shown after applying corrections for surface flux and model transport errors. Our approach to correct for transport model biases is to nudge the deviations specific to each transport model toward a reference seasonal cycle including a climatological mean offset that are calculated from the available in situ $\mathrm{CO}_{2}$ measurements for the past decades. Furthermore, we adopt a multitransport model approach in order to reduce the error in individual model transport. The ensemble mean of multiple models is anticipated to produce a more robust $3-\mathrm{D} \mathrm{CO}_{2}$ field than that derived from a single model, which has been shown for synoptic scale variations at surface measurement sites [Patra et al., 2008].

[5] The remainder of this paper is organized as follows. In Section 2 we present the transport models considered in the present analysis, and in Section 3 explain the methods employed to correct for model biases in the troposphere, the stratosphere and eco-regions. The results are discussed in Section 4, followed by a summary of the main conclusions of this study in section 5 .

\section{Transport Models}

[6] This study makes use of 3-D hourly $\mathrm{CO}_{2}$ concentrations, simulated as part of the Transcom satellite experimental protocol (Maksyutov et al., unpublished report, 2007), by the following tracer transport models: ACTM [Patra et al., 2009], LMDZ4 [Hourdin et al., 2006], NICAMbased transport model [Miura, 2007; Satoh et al., 2008; Niwa et al., 2011], NIES08 [Maksyutov et al., 2008; Belikov et al., 2011], PCTM [Kawa et al., 2004], and TM5 [Krol et al., 2005]. The models are briefly described in Table 1 . The $\mathrm{CO}_{2}$ simulations follow the similar experimental set up as was used for the TransCom continuous experiment [Law et al., 2008], except that global 3-D hourly model output was collected for the years 2002 and 2003 after a 2-year model spin-up. To assess the dependence of the simulated $\mathrm{X}_{\mathrm{CO} 2}$ on the surface flux we have prepared two types of $\mathrm{CO}_{2}$ fluxes: (1) three-hourly CarbonTracker (hereafter CT) output [Peters et al., 2007] and (2) a set of the Transcom continuous fluxes (TF) composed of three-hourly biosphere model fluxes [Olsen and Randerson, 2004], annual mean fossil-fuel emissions [Olivier and Berdowski, 2001], the global fire emissions [van der Werf et al., 2006] and monthly mean ocean fluxes [Takahashi et al., 2002].

[7] To create an ensemble mean climatology using simulations from the six transport models on their native model grids, we have remapped the model-derived $\mathrm{X}_{\mathrm{CO} 2}$ fields to a common coordinate system. A finer spatial grid resolution than that of the participating transport models is not desired for the climatology, since our approach smoothes the fine scale $\mathrm{CO}_{2}$ variability. We selected a horizontal resolution of $2.5^{\circ}$ latitude by $2.5^{\circ}$ longitude and 21 sigma pressure levels in the vertical $(1,0.975,0.95,0.925,0.9,0.85,0.8,0.7$, $0.6,0.5,0.4,0.3,0.25,0.2,0.15,0.1,0.07,0.05,0.03,0.02$, and 0.01 ), spanning the altitude range from the surface up to approximately $30 \mathrm{~km}$. Remapping of the transport model output was achieved by trilinear interpolation using the values at the eight nearest grid points. The total $\mathrm{CO}_{2}$ column mean mixing ratio was calculated from the remapped $\mathrm{CO}_{2}$ concentrations weighted by the pressure difference over the layer, where we assumed the $\mathrm{CO}_{2}$ concentration at the top of the atmosphere to be that of the sigma level 0.01. The model output was sampled once per day at 13:00 local time for the sun-synchronous satellite orbit. Seasonal and synoptic cycles were selected from the sampled daily variation using a 36-day moving average band-pass filter as discussed below.

[8] Table 2 compares time series of the selected seasonal and synoptic $\mathrm{X}_{\mathrm{CO} 2}$ variations among the six transport models. Values above the diagonal represent the correlation between $\mathrm{X}_{\mathrm{CO} 2}$ time series in 2002, sampled at all grid points; values below the diagonal are Tukey's test statistic $q$ for a multicomparison test of the correlations. In this test the null hypothesis $\left(\mathrm{H}_{0}\right)$ is that no significant difference exists between the correlations; the alternative hypothesis $\left(\mathrm{H}_{1}\right)$ is that this difference is significant. The brief summary of the values of the test statistic $q$ reveals similar results for all models. All values of the test statistic $q$ were less than 4.28 , corresponding to a significance level of $10 \%$, which means that the correlations for all models lie in the two-sided $90 \%$ confidence interval. Therefore, we fail to reject the null hypothesis, that is, the seasonal cycles of the six models can be assumed to have an almost similar phase and amplitude. On the other hand, the test statistics shows larger values for synoptic variability than those for seasonal variability, indicating weak evidence against the null hypothesis at the synoptic scale. Point estimates of the population correlation coefficient yielded values of $0.986,0.980,0.65$, and 0.79 for seasonal CT, seasonal TF, synoptic CT, and synoptic TF. The main part of the analysis in this study involves the use of the CT flux because of the high correlation. The 36-day time window used for the moving average was assumed to be the maximum value of the point estimates of the seasonal CT. Because seasonal variations in $\mathrm{X}_{\mathrm{CO} 2}$ are similar among the six transport models, the ensemble climatology that has been 
Table 1. Transport Models Employed in the TransCom Satellite Experiment

\begin{tabular}{|c|c|c|c|c|}
\hline \multirow[b]{2}{*}{ Model } & \multirow[b]{2}{*}{ Contributor } & \multicolumn{2}{|c|}{ Resolution } & \multirow[b]{2}{*}{ Meteorology ${ }^{b}$} \\
\hline & & Horizontal & Vertical $^{\mathrm{a}}$ & \\
\hline ACTM & RIGC & $\mathrm{T} 42\left(\sim 2.8^{\circ} \times \sim 2.8^{\circ}\right)$ & $32 \sigma$ & NCEP; $U, V, T$ \\
\hline LMDZ4 & LSCE & $3.75^{\circ} \times 2.5^{\circ}$ & $19 \eta$ & LMDZ/ECMWF \\
\hline NICAM & AORI & $\sim 240 \mathrm{~km} \times \sim 240 \mathrm{~km}$ & $40 z^{*}$ & JRA-25; $U, V$ \\
\hline NIES08 & NIES & $2.5^{\circ} \times 2.5^{\circ}$ & $32 \theta$ & JRA-25 \\
\hline PCTM & $\mathrm{CSU}$ & $1.25^{\circ} \times 1^{\circ}$ & $25 \sigma$ & NASA/GSFC/GEOS4 \\
\hline TM5 & SRON & $3^{\circ} \times 2^{\circ}$ & $25 \eta$ & ECMWF \\
\hline
\end{tabular}

${ }^{\mathrm{a}}$ The $\sigma$ are sigma coordinates (pressure normalized by surface pressure); $\eta$ are hybrid sigma-pressure coordinates; $z^{*}=z_{\mathrm{T}}\left(z-z_{\mathrm{S}}\right) /\left(z_{\mathrm{T}}-z_{\mathrm{S}}\right)$ is a terrainfollowing coordinate, where $z_{\mathrm{S}}$ is surface height and $z_{\mathrm{T}}$ is the height of the top of the model domain; and the $\theta$ is a hybrid sigma-theta coordinate.

${ }^{\mathrm{b}} U, V$, and $T$ are parameters used in the online models, but not in offline models.

created from them is expected to be more robust than using a single model. Note that this similarity among the models may not necessarily imply a high correlation between simulated and true $\mathrm{CO}_{2}$ concentrations.

\section{Correction of Model Bias}

[9] We have used a technique of nudging and interpolation, with sufficient efficiency to construct a climatological $\mathrm{CO}_{2}$ distribution. The seasonal cycle of the transport models can be nudged toward a seasonal cycle of extended $\mathrm{CO}_{2}$ record $[G L O B A L V I E W-C O 2,2010]$ that is a data product of in situ $\mathrm{CO}_{2}$ measurements from surface stations, towers, ships and aircraft measurements for the period from 1979 to 2009. The reference $\mathrm{CO}_{2}$ climatology $\left(\mathrm{CO}_{2}^{\mathrm{REF}}\right)$, used in this study, was created by filtering out interannual anomalies and synoptic variability in the extended $\mathrm{CO}_{2}$ records using a curve-fitting procedure [Masarie and Tans, 1995]. Results are made available as a reference time series that is composed of a climatological mean offset, trend and seasonal cycle. However, the availability of in situ $\mathrm{CO}_{2}$ restricted to GLOBALVIEW sites made it difficult to estimate the bias at regions located away from the measurement network.

[10] We attempt to estimate a 3-D bias distribution by filling the data gaps in a correction field between the sites. This approach is applied to each of the transport models, yielding six bias-corrected 3-D $\mathrm{CO}_{2}$ climatology that are then averaged to produce what is referred to as the Gap- filled and Ensemble Climatology Mean (GECM). GECM can be used to predict a reference $3-\mathrm{D} \mathrm{CO}_{2}$ state $\left(\mathrm{CO}_{2}^{\mathrm{GECM}}\right)$ corresponding to the times and coordinates of satellite measurements. On the other hand, the ensemble mean of the six transport models is dubbed the Ensemble Climatology Mean (ECM).

\subsection{Tropospheric Bias}

[11] We have interpolated the 3-D bias field using two approaches: (1) nudging for known grid points for which measurements are available, and (2) interpolation for the remaining grid points (hereafter an interpolation grid). The nudging approach simply removes the biases at known grid points by replacing the modeled concentration with the corresponding $\mathrm{CO}_{2}^{\mathrm{REF}}$. For the interpolation grid points, we used the model-simulated concentrations corrected for the interpolated 3-D bias. The interpolation method is a hybrid one between inverse distance weighting (IDW) and natural neighbor interpolation (NNI) [Watson, 1992], adopted as a compromise between computing cost and accuracy in interpolated values away from sparsely distributed observation sites. Other interpolation methods, such as kriging and radical basis function, are computationally expensive and do not guarantee unbiased results for the known grid points. IDW satisfies the latter criterion, while NNI weakens unnatural peak-and-trough patterns at interpolation grid boxes and works faster than other interpolation methods because it involves only a small number of parameters.

Table 2. General Statistical Comparison of the Participating Transport Models ${ }^{\mathrm{a}}$

\begin{tabular}{|c|c|c|c|c|c|c|c|c|c|c|c|c|c|}
\hline & & \multicolumn{12}{|c|}{ Correlation } \\
\hline & & \multicolumn{6}{|c|}{$\mathrm{CT}$} & \multicolumn{6}{|c|}{$\mathrm{CS}$} \\
\hline \multicolumn{2}{|c|}{ Test Statistic: $\mathrm{q}$} & ACTM & LMDZ4 & NICAM & NIES08 & PCTM & TM5 & ACTM & LMDZ4 & NICAM & NIES08 & PCTM & TM5 \\
\hline \multirow[t]{6}{*}{ Season } & ACTM & & 0.988 & 0.987 & 0.984 & 0.961 & 0.977 & & 0.988 & 0.993 & 0.989 & 0.994 & 0.963 \\
\hline & LMDZ4 & 0.473 & & 0.986 & 0.983 & 0.967 & 0.965 & 0.470 & & 0.987 & 0.990 & 0.991 & 0.956 \\
\hline & NICAM & 0.219 & 0.254 & & 0.975 & 0.960 & 0.966 & 0.344 & 0.126 & & 0.985 & 0.992 & 0.958 \\
\hline & NIES08 & 0.580 & 0.107 & 0.361 & & 0.941 & 0.954 & 0.494 & 0.024 & 0.150 & & 0.987 & 0.950 \\
\hline & PCTM & 0.317 & 0.789 & 0.536 & 0.897 & & 0.940 & 0.071 & 0.540 & 0.415 & 0.565 & & 0.964 \\
\hline & TM5 & 0.479 & 0.952 & 0.698 & 1.059 & 0.163 & & 0.704 & 1.174 & 1.048 & 1.198 & 0.634 & \\
\hline \multirow[t]{6}{*}{ Synoptic } & ACTM & & 0.763 & 0.751 & 0.560 & 0.657 & 0.640 & & 0.877 & 0.884 & 0.842 & 0.881 & 0.668 \\
\hline & LMDZ4 & 1.200 & & 0.750 & 0.581 & 0.599 & 0.518 & 1.137 & & 0.830 & 0.844 & 0.858 & 0.625 \\
\hline & NICAM & 0.556 & 0.644 & & 0.487 & 0.571 & 0.521 & 0.831 & 0.305 & & 0.774 & 0.825 & 0.609 \\
\hline & NIES08 & 1.475 & 0.275 & 0.919 & & 0.376 & 0.322 & 1.195 & 0.059 & 0.364 & & 0.801 & 0.606 \\
\hline & PCTM & 0.814 & 2.015 & 1.370 & 2.290 & & 0.552 & 0.171 & 1.308 & 1.002 & 1.366 & & 0.651 \\
\hline & TM5 & 1.227 & 2.427 & 1.783 & 2.702 & 0.412 & & 1.705 & 2.842 & 2.537 & 2.901 & 1.534 & \\
\hline
\end{tabular}

${ }^{\mathrm{a}}$ Boldface and nonboldface values represent correlation coefficients and a Tukey multicomparison test statistic $q$, respectively. The significance levels at $1 \%, 5 \%$, and $10 \%$ for a two-tailed test correspond to values of the test statistic $q$ of $5.29,4.62$ and, 4.28 , respectively. 


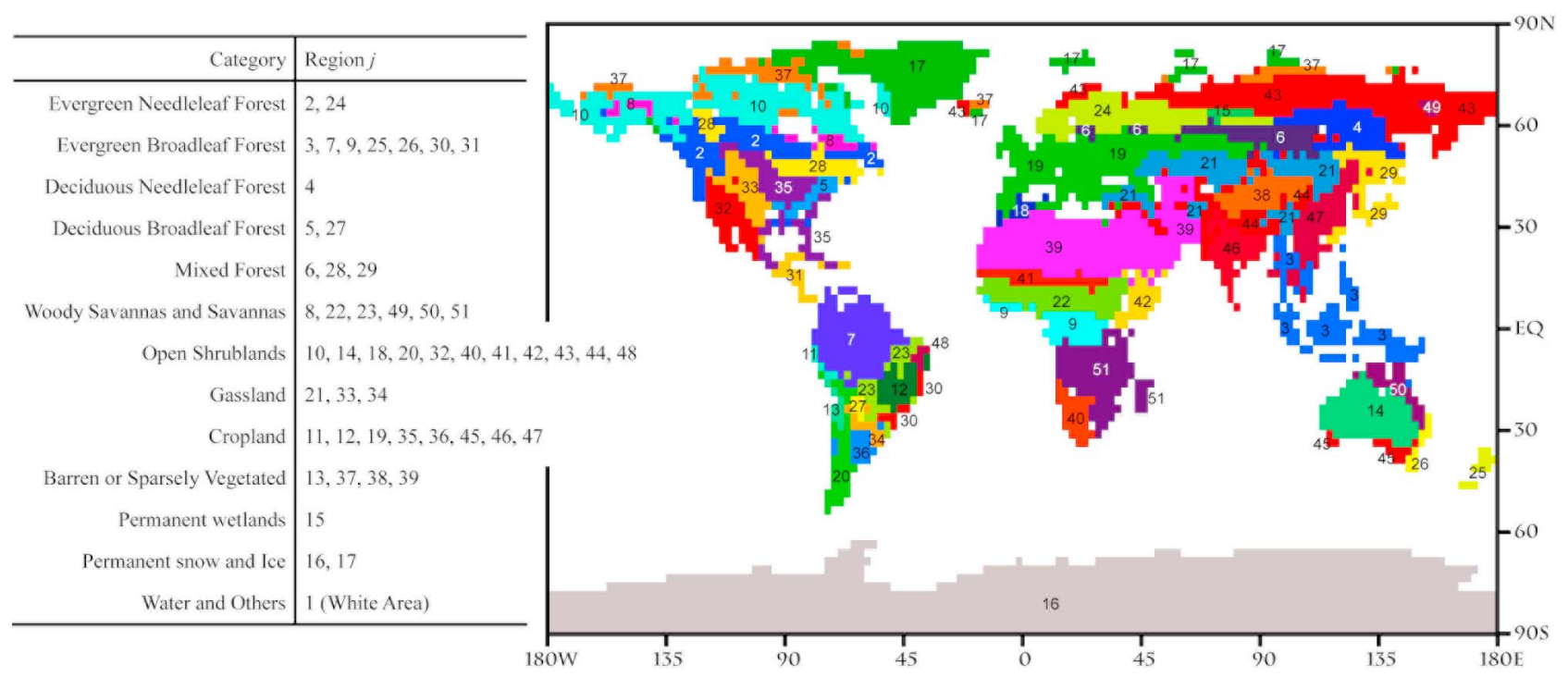

Figure 1. Global map showing the different ecosystem regions used in the minimum variance method. Horizontal resolution is $2.5^{\circ} \times 2.5^{\circ}$. The inset table lists the 13 terrestrial biome categories corresponding to the numbering in the map. The map is based on the original data from the MODIS Land Cover Group [Friedl et al., 2002].

[12] Using IDW, based on horizontal spherical interpolation at given sigma pressure levels $\sigma$, the $3 \mathrm{D}$ bias $b\left(g_{u}\right)$ for arbitrary grid points $g_{u}$ to be interpolated is represented by

$$
b\left(g_{u}\right)=f^{\mathrm{NNI}}\left(g_{u}\right) \sum_{i=1}^{I}\left(\frac{b\left(g_{i}\right)}{f^{\mathrm{NNI}}\left(g_{i}\right)} \frac{1}{d\left(g_{u}, g_{i}\right)^{p}}\right) / \sum_{i=1}^{I} \frac{1}{d\left(g_{u}, g_{i}\right)^{p}},
$$

where IDW generally used power $p=2$, the subscript $i$ is the known grid index, $I$ is the number of known grid points $g_{i}$, the subscript $u$ is the interpolation grid index, $d$ is the horizontal spherical distance between $g_{i}$ and $g_{u}$, and $f^{\mathrm{NNI}}$ is a spatial anisotropy factor (see below for details). The temporally and spatially varying bias $b\left(g_{i}\right)$ of the transport model is the difference between $\mathrm{CO}_{2}^{\mathrm{REF}}$ and $\mathrm{CO}_{2}^{\mathrm{ECM}}$ at known grids.

[13] To find the known grid $b\left(g_{i}\right)$ in the troposphere, we used $\mathrm{CO}_{2}^{\mathrm{REF}}$ from GLOBALVIEW surface stations, towers, ships and aircraft measurements. The coordinates of measurement locations were arranged along the GECM coordinate below $\sigma=0.25$. The Western Pacific Ocean (WPO; marked by white circles in Figure 2a) measurements along the aircraft cruising altitude correspond to about $250 \mathrm{hPa}$ $(\sigma \sim 0.25)$, which is the maximum height considered in GECM optimization. The locations of vertical profiles by aircraft measurements are marked by the green symbols in Figure 2a, which include data at 4-6 vertical levels at an interval of $1000 \mathrm{~m}$ in the free troposphere. Duplicate $\mathrm{CO}_{2}^{\mathrm{REF}}$ values that are available for the same grid box were averaged, and surface station heights were specified to be at $\sigma=1$. Several stations, representing the marine boundary layer were assumed to be at the $\sigma=1$. Surface stations located on islands or in coastal regions where $\mathrm{CO}_{2}$ concentrations are generally only weakly influenced by regional emissions were assumed to be sigma levels corresponding to each height above sea level. This procedure has been applied to the eight surface stations: Bukit Kototabang (BKT), Canary Islands (IZO), Mauna Loa (MLO), Olympic Peninsula (OPW), Mt. Cimone (CMN), Pic Du Midi (PDM), Negev Desert (WIS), and South Pole (SPO). All GLOBALVIEW stations were used except Black Sea (BSC), which introduced a large bias due to coastal circulation and strong local flux gradients [Pérez-Landa et al., 2007]. In total, 228 GLOBALVIEW records, including 113 surface stations, were used for GECM.

[14] In this study, the distance weighting term $1 / d\left(g_{u}, g_{i}\right)^{p}$ in equation (1) is parameterized by a spatial anisotropy function to determine how the values are interpolated horizontally. We defined the spatial anisotropy factor $f^{\mathrm{NNI}}$ at a given sigma level as:

$$
f^{\mathrm{NNI}}=P_{r} b^{\text {Const }}+\left(1-P_{r}\right) b^{\mathrm{NNI}}
$$

where $P_{r}$ is a parameter that describes the weight ratio between a constant bias $b^{\text {Const }}$ and the interpolated bias $b^{\mathrm{NNI}}$. The constant bias $b^{\text {Const }}$ was defined as the global average bias in the free troposphere. The horizontal distribution of bias $b^{\mathrm{NNI}}$ was determined by NNI using spherical Delaunay triangulation (black lines in Figure 2) with Voronoi generators corresponding to $b\left(g_{i}\right)$ at the known grids. The area of the triangles on the Earth's surface was larger over South America, Africa and Southern Hemisphere oceans than over other regions, reflecting the scarcity of known grid points in these areas. For the interpolation grid points, the interpolated bias $b^{\mathrm{NNI}}$ was distributed horizontally along the circumference of $g_{i}$, as defined by $P_{r}$. Vertexes on the fine triangle mesh (e.g., over Central Asia, Europe, and North America) are sometimes located adjacent to known grid boxes. IDW and NNI interpolation between adjacent known grids were ignored.

[15] Bias corrections at every layer below $\sigma=0.25$ followed the above process. However, because of the scarcity of GLOBALVIEW stations at the second layer $(\sigma=0.975)$ 
(a) Interpolated Bias

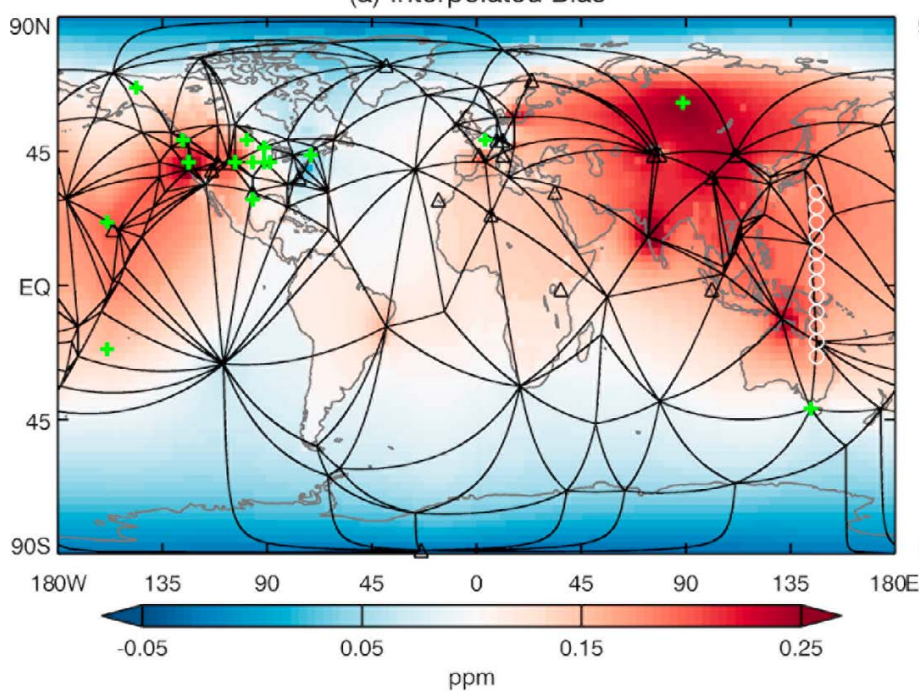

(b) Interpolated Bias

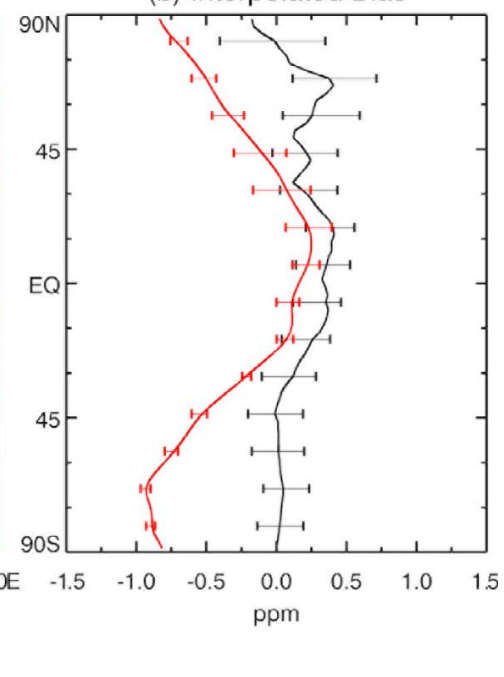

Figure 2. (a) Annual mean interpolated bias $B$ at the surface (GECM minus ECM). Black lines denote the edges of spherical Delaunay triangles with known surface grids. The transport modeling results are offset by the annual mean concentration at the South Pole. Black triangles, green pluses, and white circles present locations for aircraft profiles, on high lands and mountains, and aircraft measurements near the tropopause, respectively. (b) Annual zonal mean interpolated bias $B$ of the surface (black line) and of the column mean (red line). Horizontal bars show 1 standard deviation above and below the annual mean.

and the fourth layer $(\sigma=0.925)$ in GECM, the bias of these layers was defined as the average over values at both up and down layers.

\subsection{Surface Regional Bias}

[16] Figure 1 shows a global map distinguishing 51 regions based on 13 types of ecosystems, as characterized in the land cover classification of the International GeosphereBiosphere Programme (IGBP). This regional classification is resampled from a land cover data set [Friedl et al., 2002]. The ecosystem categories, listed in the legend in Figure 1, correspond to the region index $j$, as indicated by the numbers in the map. In the case of sparse spatial observations (e.g., the GLOBALVIEW data set), it is difficult to parameterize a regionally varying bias that depends on land-ocean differences and varied terrestrial ecosystem types away from observation sites, especially Amazon $(j=7)$, Central Africa $(j=9$ and 22), and Siberia $(j=43)$ due to strong sources and sinks within the large Delaunay triangulations. The biases on each region $j$ have not only been corrected using the hybrid interpolation method, but also statistically estimated by a minimum variance method using the six transport model simulations.

[17] Because the $\mathrm{CO}_{2}$ concentrations of all the transport models were nudged toward $\mathrm{CO}_{2}^{\mathrm{REF}}$ at known grid points, the variance of $\mathrm{CO}_{2}$ concentrations among the transport models should be zero; however, nonzero variances are found for interpolation grid points where $\mathrm{CO}_{2}$ concentrations were estimated by the interpolation method. The variance $v$ at an interpolation grid point at a time of the seasonal cycle is obtained using the following equation:

$$
v=\frac{1}{M} \sum_{m=1}^{M}\left(x_{m}-\bar{x}\right)^{2},
$$

where the subscript $m$ is a transport model index, $M$ is the number of the transport models ( $M=6$ in this study), $x_{m}$ is a native transport model concentration with the addition of the interpolated bias $b_{m}$, and $\bar{x}$ is the mean value of $x_{m}$.

[18] The regional bias parameter $r_{m}$ is added to the interpolated bias $b$ that is obtained from equation (1), and optimized such that the variance $v$ is minimized. Therefore, the interpolated $\mathrm{CO}_{2}$ concentrations (vector $\mathbf{x}_{m}$ ) in a region including several grid boxes are the sum of $r_{m}, \mathbf{b}_{m}$, and the transport model concentration $\mathbf{y}_{m}$, as follows:

$$
\mathbf{x}_{m}=r_{m}+\mathbf{b}_{m}+\mathbf{y}_{m} .
$$

Equation (4) satisfies the following vector size: $\mathbf{x}_{m} \in \mathbf{R}^{K}$, $\mathbf{b}_{m} \in \mathbf{R}^{K}$, and $\mathbf{y}_{m} \in \mathbf{R}^{K}$, where $K$ is the number of grid points in a region $j$. The region grids $g_{k}$ comprises several horizontal grids, indexed with subscript $k$, at the surface sigma level $\sigma=1$. To find the optimal $r_{m}$, the differential of the variance $v$ should be minimized. Therefore, $v$ is differentiated by $\mathbf{x}$, as follows:

$$
\frac{\mathrm{d} v}{\mathrm{~d} \mathbf{x}}=\mathbf{A r}+\mathbf{b}+\mathbf{y}-\mathbf{B}(\mathbf{A r}+\mathbf{b}+\mathbf{y})
$$

where the vectors in equation (5) are defined as follows:

$$
\begin{aligned}
& \mathbf{x}=\{ x_{k=1, m=1}, x_{k=2, m=1}, \ldots, x_{k=K, m=1}, x_{k=1, m=2}, x_{k=2, m=2}, \\
&\left.\ldots, x_{k=K, m=2}, x_{k=1, m=M}, x_{k=2, m=M}, \ldots, x_{k=K, m=M}\right\}, \\
& \mathbf{r}=\left\{r_{m=1}, r_{m=2}, \ldots, r_{m=M}\right\}, \\
& \mathbf{b}=\left\{b_{k=1, m=1}, b_{k=2, m=1}, \ldots, b_{k=K, m=1}, b_{k=1, m=2}, b_{k=2, m=2},\right. \\
&\left.\ldots, b_{k=K, m=2}, b_{k=1, m=M}, b_{k=2, m=M}, \ldots, b_{k=K, m=M}\right\}, \quad \text { and } \\
& \mathbf{y}=\left\{y_{k=1, m=1}, y_{k=2, m=1}, \ldots, y_{k=K, m=1}, y_{k=1, m=2}, y_{k=2, m=2},\right. \\
&\left.\quad \ldots, y_{k=K, m=2}, y_{k=1, m=M}, y_{k=2, m=M}, \ldots, y_{k=K, m=M}\right\}
\end{aligned}
$$




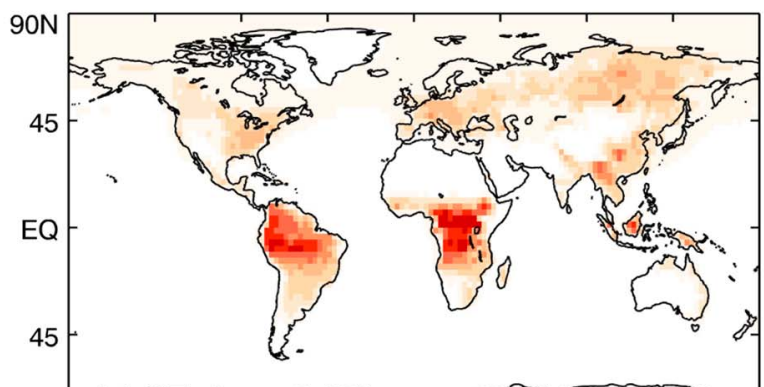

(a) SE, Avg $=0.082$

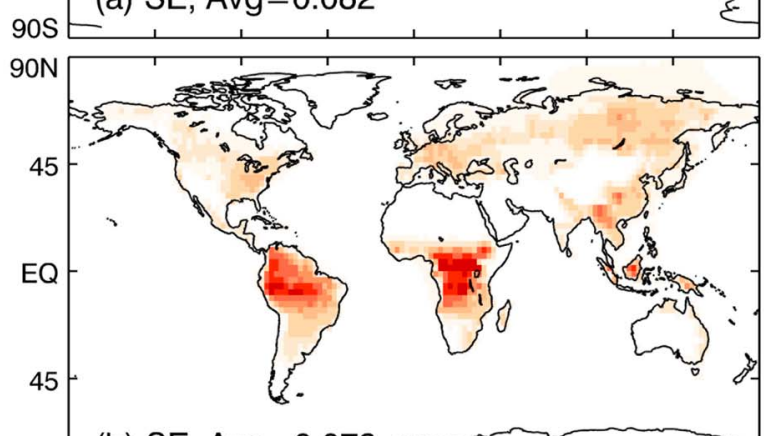

(b) $\mathrm{SE}, \mathrm{Avg}=0.073$

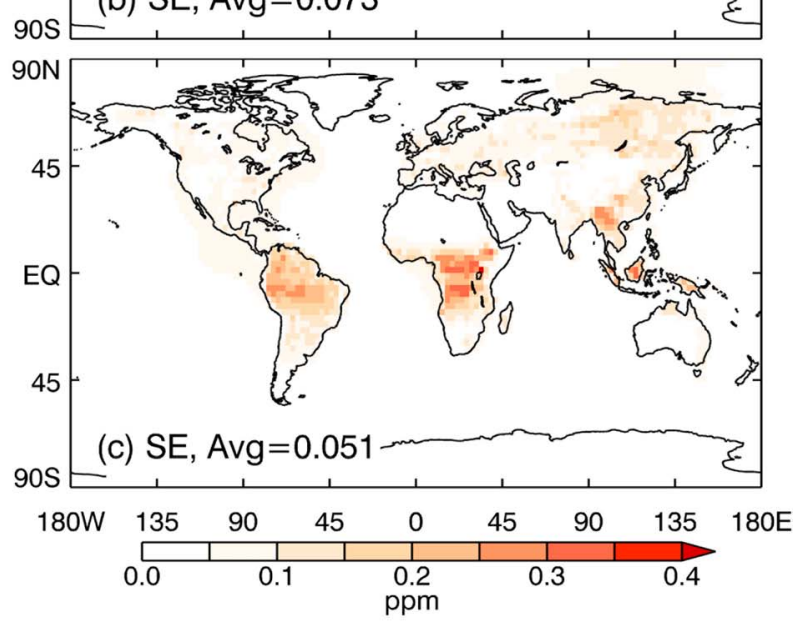

Figure 3. Standard error (SE) among the seasonal time series of multi transport model-simulated $\mathrm{CO}_{2}$ that are (a) original output, (b) corrected bias without the regional correction, and (c) corrected bias by all methods.

The non-square matrix $\mathbf{A}$ is composed of identity vectors $\mathbf{i}_{m}$ whose sizes correspond to $K$ :

$$
\mathbf{A}=\left[\begin{array}{llll}
\mathbf{i}_{1} & & & \\
& \mathbf{i}_{2} & & \\
& & \ddots & \\
& & & \mathbf{i}_{M}
\end{array}\right],
$$

and the symmetric matrix $\mathbf{B}$ is composed of the $K$-by- $K$ identity matrix $\mathbf{I}_{m}$ for operating the average mean value of the multimodel concentrations $x$ in equation (5):

$$
\mathbf{B}=\frac{1}{M}\left[\begin{array}{llll}
\mathbf{I}_{1} & \mathbf{I}_{2} & \cdots & \mathbf{I}_{M} \\
\mathbf{I}_{2} & \mathbf{I}_{2} & \cdots & \mathbf{I}_{M} \\
\vdots & \vdots & \ddots & \vdots \\
\mathbf{I}_{M} & \mathbf{I}_{M} & \cdots & \mathbf{I}_{M}
\end{array}\right] .
$$

Solving equation (5) by optimization (e.g., the conjugate gradient method and Newton method) yields the optimized vector $\mathbf{r}$, which depends on the region. Finally, the bias $b^{\mathrm{NNI}}$ on each region $j$ in equation (2) is updated by

$$
b^{\mathrm{NNI}}:=b^{\mathrm{NNI}}\left(r_{m, j} / b_{k(j), m}+1\right) .
$$

[19] A regional bias in the region index $j=1$ (oceans, water, and uncategorized regions) was not optimized because the variance has been already small enough, for which we used the constant scaling factor $r_{m}=0$. The area of uncategorized regions was too small to result in a statistically significant regional bias.

\subsection{Stratospheric Bias}

[20] The tropopause $\mathrm{CO}_{2}$ concentration propagates upward with a time lag determined by the elevation- and latitude-dependent transport time. However, IDW could not be applied above $\sigma=0.25$ because of the limited availability of stratospheric observations. As an alternative, we have corrected for the zonal mean bias $b^{\text {str }}\left(g_{y}, \sigma, t\right)$ using the mean age of air in the stratosphere, where $g_{y}$ refers to GECM latitudes and $\sigma$ is between the tropopause and upper domain boundary $(\sigma=0.01)$. The seasonally varying latitudinal and vertical distributions of the mean age of air were estimated by ACTM [Patra et al., 2009]. Typically the simulated age of stratospheric air is younger than estimations using observed vertical profiles of $\mathrm{SF}_{6}$ mixing ratio from balloon soundings in Hyderabad $\left(17^{\circ} \mathrm{N}\right)$, Aire sur $1^{\prime}$ Adour $\left(44^{\circ} \mathrm{N}\right)$, and Esrange $\left(68^{\circ} \mathrm{N}\right)$ [Harnisch et al., 1996; Patra et al., 1997]. We first calculated the percentage difference between the simulated age and $\mathrm{SF}_{6}$ measurementbased age. Then, the mean age of air in the percentage differences were corrected for the stratospheric GECM grids over latitude bands $17^{\circ} \mathrm{S}-17^{\circ} \mathrm{N}$ using the profiles in Hyderabad, $17^{\circ} \mathrm{N}-44^{\circ} \mathrm{N}$ and $17^{\circ} \mathrm{S}-44^{\circ} \mathrm{S}$ using interpolated profiles between Hyderabad and Aire sur l'Adour, $44^{\circ} \mathrm{N}-$ $68^{\circ} \mathrm{N}$ and $44^{\circ} \mathrm{S}-68^{\circ} \mathrm{S}$ using those between Aire sur l'Adour and Esrange, and polewards than $68^{\circ} \mathrm{N}$ and $68^{\circ} \mathrm{S}$ using the profiles in Esrange (refer to the supplementary materials for further details).

[21] Eventually, a top boundary $\mathrm{CO}_{2}$ concentration was the tropopause $\mathrm{CO}_{2}$ concentration corrected for the time lag corresponding to the mean age of air and without seasonal variation. A zonal mean of the tropopause $\mathrm{CO}_{2}$ concentration was assumed to be the latitudinal interpolation of $\mathrm{CO}_{2}^{\mathrm{REF}}$ at WPO of latitudes $25^{\circ} \mathrm{S}-30^{\circ} \mathrm{N}$ and ECM's concentrations at both Poles. The seasonal tropopause height was taken from the NCEP/NCAR Reanalysis for mid to low latitudes and was assumed to be at $\sigma=0.3$ near the North and South Poles. The seasonal phase and zonal mean of $\mathrm{CO}_{2}^{\mathrm{GECM}}$ was shifted from the tropopause $\mathrm{CO}_{2}$ concentration in accordance with the corrected mean age of air. Thus, we have estimated the zonal mean $\mathrm{CO}_{2}$ concentrations between the tropopause and upper domain boundary. The zonal mean bias $b^{\text {str }}\left(g_{y}, \sigma, t\right)$ has been calculated from the zonal mean of the transport model output minus the estimated $\mathrm{CO}_{2}$ concentrations. The bias between the tropopause and $\sigma=0.25$ was linearly interpolated using the zonal mean tropopause bias $b^{\text {str }}\left(g_{y}, \sigma, t\right)$ and the bias $b(g, 0.25, t)$ at each horizontal grid box. The stratospheric $\mathrm{CO}_{2}^{\mathrm{GECM}}$, represented by $b^{\mathrm{str}}\left(g_{y}, \sigma, t\right)$ plus the transport 
(a) Surface Seasonal Amplitude

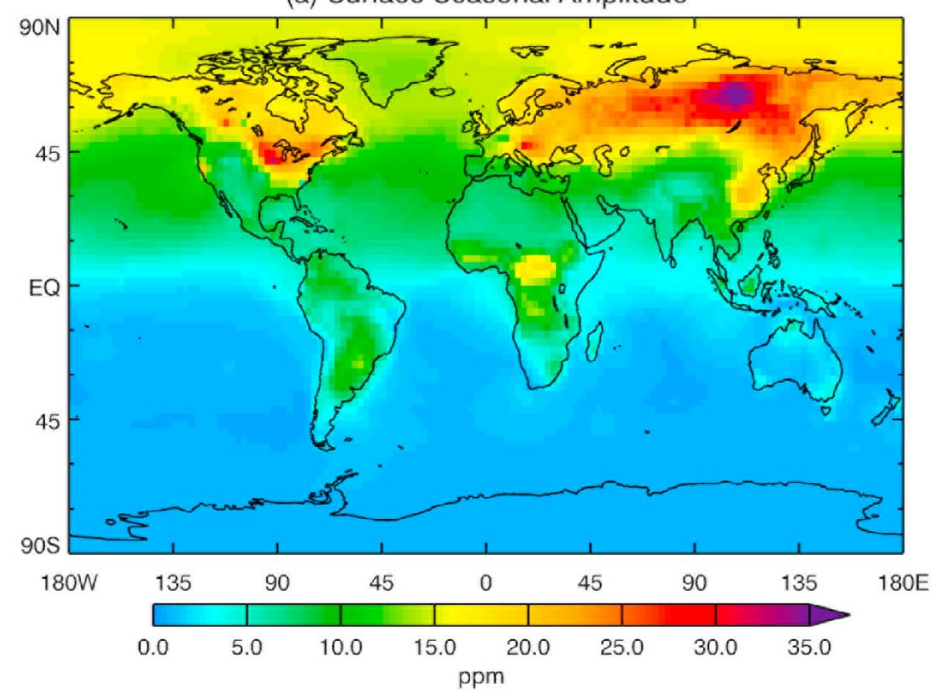

(b) Seasonal Amplitude

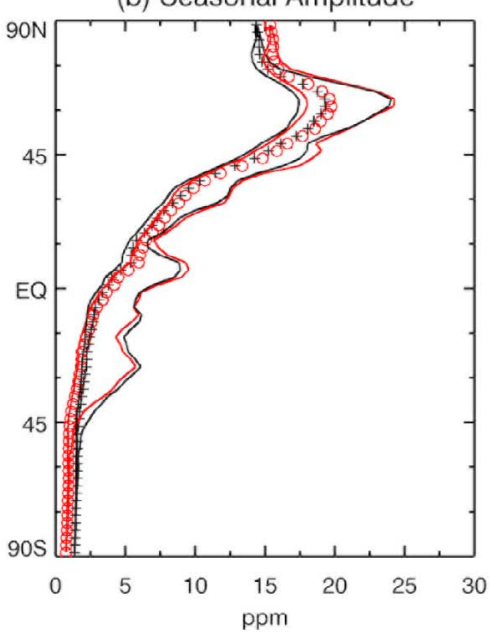

Figure 4. (a) Horizontal distribution of the surface peak-to-peak seasonal amplitude of $\mathrm{CO}_{2}^{\mathrm{GECM}}$. (b) Zonal mean surface seasonal amplitudes of $\mathrm{CO}_{2}^{\mathrm{GECM}}$ (red circles) and $\mathrm{CO}_{2}^{\mathrm{ECM}}$ (black 'plus' symbols). Solid lines denote 1 standard deviation above and below the zonal mean.

modeling result, retained horizontal distribution patterns driven by the native transport model.

\section{Results and Discussion}

\subsection{Horizontal Distribution of the Corrected Bias}

[22] Figure 2a shows the multimodel mean of the annual mean interpolated bias that was vertical column averaged near the surface (from the surface up to $\sigma=0.7$ ). Large annual mean biases greater than $0.2 \mathrm{ppm}$ were found over the Pacific Ocean, Eurasia, and coastal regions in Southeast Asia and Australia. These areas, which correspond to a fine network of Delaunay triangles, were better correlated to $\mathrm{CO}_{2}^{\mathrm{REF}}$. The interpolated biases around the known grids mainly depended on IDW. On the other hand, the regional correction factor $r_{m}$ in equation (4) strongly influenced the regional bias in remote areas away from the observation sites, especially Africa and South America where a landocean contrast was obvious, and horizontal patterns by IDW was weaken. Over the ocean regions relatively small corrections were obtained, where the homogeneous pattern of corrections depended mainly on NNI and the parameter $r_{m}$.

[23] The annual zonal mean bias at the surface (black line in Figure 2b) was corrected by $0.2 \mathrm{ppm}$ in the Southern Hemisphere and by $0.5 \mathrm{ppm}$ in the Northern Hemisphere. The annual zonal and vertical column averaged bias (red line in Figure 2b) was positive at all latitudes, due to the stratospheric bias. The largest biases $(\sim 1 \mathrm{ppm})$ are found at high latitudes.

\subsection{Performance of Regional Bias Corrections at the Surface}

[24] To quantify the influence of our interpolation algorithm, Figure 3 compares the standard errors of the surface $\mathrm{CO}_{2}^{\mathrm{ECM}}$ (Figure 3a), $\mathrm{CO}_{2}^{\mathrm{GECM}}$ (Figures 3b) without only correction for the regional bias, and $\mathrm{CO}_{2}^{\mathrm{GECM}}$ (Figure 3c) with all the corrections. The standard error averaged over lands (see the 'Avg' value in each panel title) showed a decrease from $0.082 \mathrm{ppm}$ in Figure $3 \mathrm{a}$ to $0.073 \mathrm{ppm}$ in Figure $3 \mathrm{~b}$ and 0.051 in Figure $3 \mathrm{c}$. Therefore, GECM corrected for the regional bias showed an average reduction in error of $39 \%$ compared with the case without the correction. In more detail, the error in ECM was uniformly distributed at latitudes north of $45^{\circ}$ in the Northern Hemisphere, because the offset of the transport models was normalized by the $\mathrm{CO}_{2}$ concentration at the South Pole. Application of the IDW and NNI methods reduced this error by several parts per million (see Figure $3 \mathrm{~b}$ ). In particular, ocean regions showed a small error $(<0.03 \mathrm{ppm})$, whereas large regional errors $(>0.25 \mathrm{ppm})$ remained for the Amazon, Central Africa, and Southeast Asia. These large errors were reduced to less than $0.2 \mathrm{ppm}$ following correction for regional bias. Relatively small errors $(\sim 0.05 \mathrm{ppm})$ were found for North America and Europe, due to the high density of stations in the observation network in these regions.

[25] There were few surface stations in the nearby center of a large Delaunay triangle, where the regional bias in areas with interpolation grids was estimated from a small number of in situ observations in surrounding oceans (e.g., Amazon and Central Africa). Despite the strong $\mathrm{CO}_{2}$ sources and sinks that are provided by areas such as forest and coastal regions, the Delaunay triangles in the tropics and Siberia were too large to reduce the regional bias, causing the variance to remain in uncorrelated regions (Figure $3 \mathrm{~b}$ ). The application of the regional correction resulted in a reduced standard error (Figure 3c), especially for Siberia, Southeast Asia, the Amazon, and Central Africa, which had smaller errors $(<0.2 \mathrm{ppm})$ than the above results. Therefore, this method provides a statistically robust estimate of the concentration over these regions, whereas the actual concentration remains poorly known because of a lack of in situ $\mathrm{CO}_{2}$ records.

\subsection{Seasonal Amplitude}

[26] Large seasonal amplitude in $\mathrm{CO}_{2}^{\mathrm{GECM}}$ at the surface was seen at high latitudes in the Northern Hemisphere (Figure $4 \mathrm{a}$ ). In addition, the spotted patterns of large sea- 


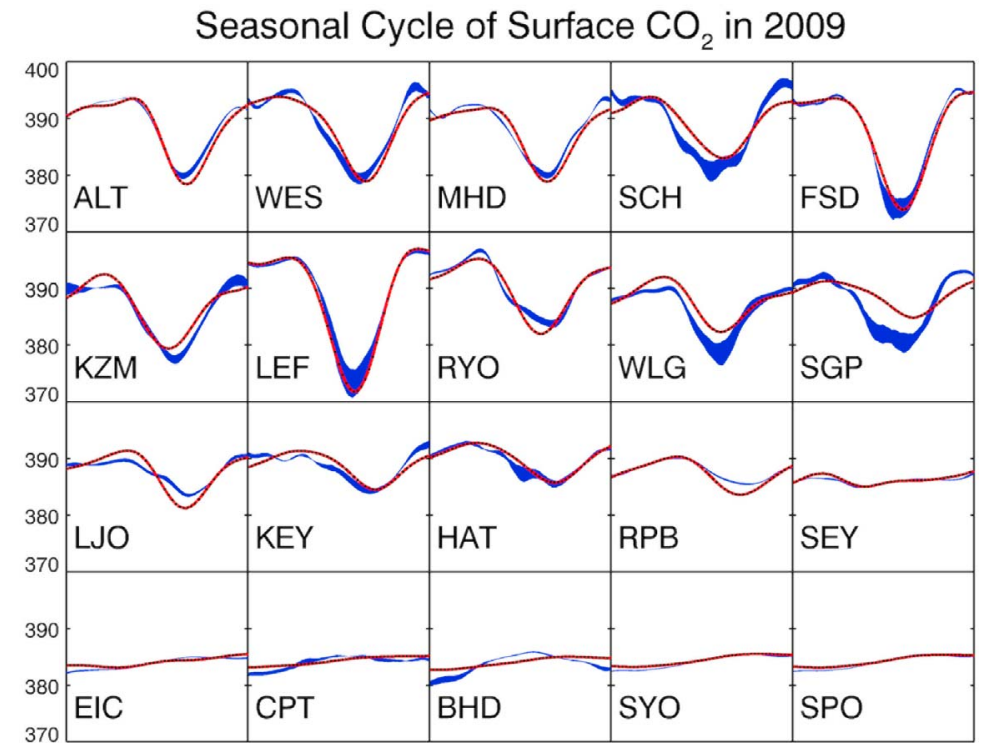

Figure 5. Seasonal cycles of the simulations $\left(\mathrm{CO}_{2}^{\mathrm{GECM}}\right.$ : red lines and $\mathrm{CO}_{2}^{\mathrm{ECM}}$ : blue lines) and in situbased $\mathrm{CO}_{2}\left(\mathrm{CO}_{2}^{\mathrm{REF}}\right.$ : black dots) at several surface sites in 2009. Blue shades represent 1 sigma standard deviations of the multi transport modeling results in $\mathrm{CO}_{2}^{\mathrm{ECM}}$.
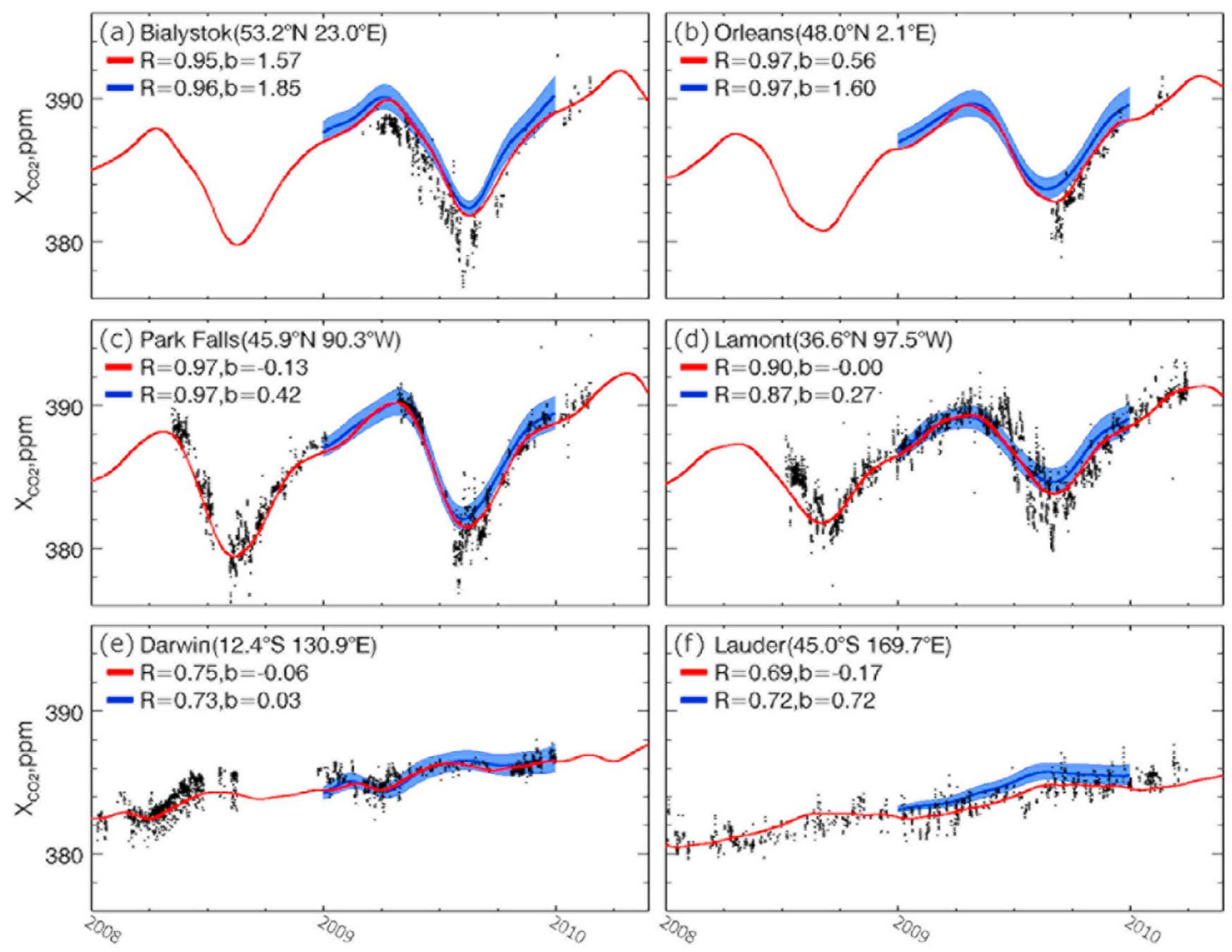

Figure 6. Time series of simulated $\left(\mathrm{X}_{\mathrm{CO} 2}^{\mathrm{GECM}}\right.$ : red lines and $\mathrm{X}_{\mathrm{CO} 2}^{\mathrm{ECM}}$ : blue lines) and observed (TCCON: black dots) $\mathrm{X}_{\mathrm{CO} 2}$ at TCCON sites. The offset of $\mathrm{X}_{\mathrm{CO} 2}^{\mathrm{ECM}}$ was normalized by the $\mathrm{CO}_{2}$ concentration at the South Pole. Blue shades represent 1 sigma standard deviations of the multi transport modeling results in $\mathrm{X}_{\mathrm{CO} 2}^{\mathrm{ECM}}$. Correlations $R$ against TCCON data and annual mean bias $b$ are presented in the legend. 
(a) Simulated profile in $2009,35^{\circ} \mathrm{N}-45^{\circ} \mathrm{N}$

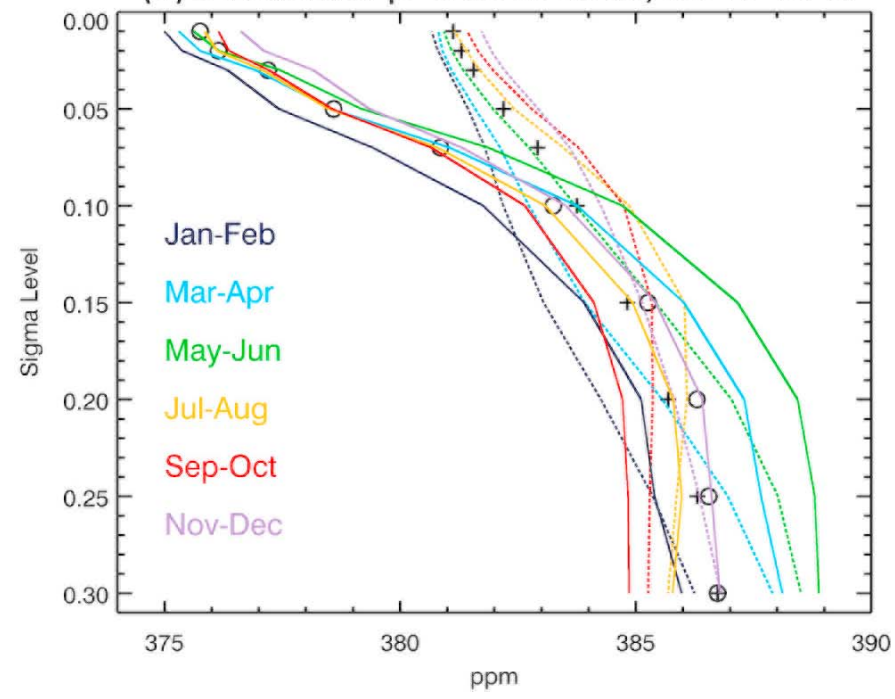

(b) Simulated profile in $2009,10^{\circ} \mathrm{S}-10^{\circ} \mathrm{N}$

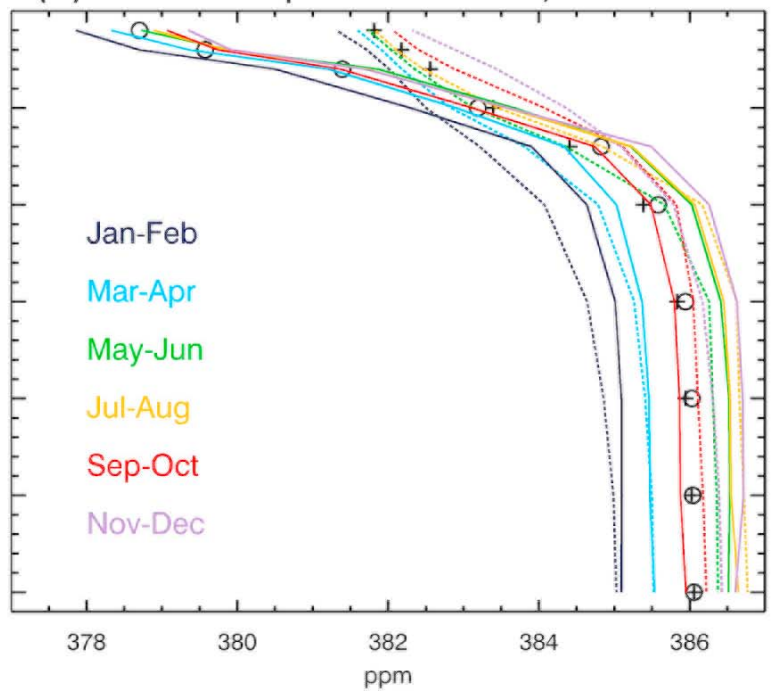

Figure 7. Vertical profiles of annual and seasonal zonal mean $\mathrm{CO}_{2}^{\mathrm{GECM}}$ (circles and solid lines) and $\mathrm{CO}_{2}^{\mathrm{ECM}}$ ('plus' symbols and dotted lines) for the region (a) $35^{\circ} \mathrm{N}-45^{\circ} \mathrm{N}$ and (b) $10^{\circ} \mathrm{S}-10^{\circ} \mathrm{N}$. This $\mathrm{CO}_{2}^{\mathrm{ECM}}$ has been offset to match $\mathrm{CO}_{2}^{\mathrm{GECM}}$ at $\sigma=0.3$ to highlight stratospheric differences.

sonal amplitude in tropical Central Africa and the boreal region of East Siberia were seen. The global distribution of surface $\mathrm{CO}_{2}^{\mathrm{GECM}}$ depends on the surface flux of CarbonTracker used in the transport models. Indeed, the seasonal amplitude of the global $1^{\circ} \times 1^{\circ}$ land flux data set (CarbonTracker 2008, http://carbontracker.noaa.gov) shows similar global distribution to that of surface $\mathrm{CO}_{2}^{\text {GECM }}$. The seasonal amplitude in $\mathrm{CO}_{2}^{\mathrm{GECM}}$, which was based on daylight hours (13:00 local time) as mentioned in Section 2, can be attributed to strength of seasonally varying photosynthesis within the forested regions.

[27] We have compared the simulated seasonal cycles with and without bias correction (Figure 4b). Zonal mean distributions of both were fairly similar to each other. Both seasonal amplitude of the surface $\mathrm{CO}_{2}^{\mathrm{ECM}}$ and $\mathrm{CO}_{2}^{\mathrm{GECM}}$ were below $\sim 2 \mathrm{ppm}$ in the Southern Hemisphere and $20 \mathrm{ppm}$ for lands in the Northern Hemisphere. This large interhemispheric gradient has been produced by differences of a midlatitude forest area within each Hemisphere. The zonal mean (red circles in Figure $4 \mathrm{~b}$ ) in the tropics was $\sim 1 \mathrm{ppm}$ higher than $\mathrm{CO}_{2}^{\mathrm{ECM}}$ (black 'plus' symbols). The maximum mismatch in standard deviation (lines in Figure $4 \mathrm{~b}$ ) is $\sim 1 \mathrm{ppm}$, found at $0-20^{\circ} \mathrm{N}$ and $45^{\circ} \mathrm{N}$. Peak-to-peak zonal mean seasonal amplitudes of $\mathrm{CO}_{2}^{\mathrm{GECM}}$ and $\mathrm{CO}_{2}^{\mathrm{ECM}}$ near $60^{\circ} \mathrm{N}$ are $\sim 25 \mathrm{ppm}$, several parts per million higher than that predicted previously [Gurney et al., 2004]. The deeper seasonality can be explained by better-resolved seasonal cycles using time series with a daily step, compared to the monthly means in the earlier study.

[28] The seasonal amplitude in $\mathrm{CO}_{2}^{\mathrm{GECM}}$ at the observation stations, corresponding to the known grids, was the same as that in $\mathrm{CO}_{2}^{\mathrm{REF}}$. Figure 5 shows that the 2009's seasonal cycles in $\mathrm{CO}_{2}^{\mathrm{GECM}}$ (green lines), $\mathrm{CO}_{2}^{\mathrm{ECM}}$ (blue lines), and $\mathrm{CO}_{2}^{\mathrm{REF}}$ (black dots) are highly correlated with each other, especially the $\mathrm{CO}_{2}^{\mathrm{GECM}}$ and $\mathrm{CO}_{2}^{\mathrm{REF}}$ which were same concentrations through the influence of IDW. The seasonal cycle in $\mathrm{CO}_{2}^{\mathrm{ECM}}$ shows a mismatch with a nearby peak and trough in the annual $\mathrm{CO}_{2}^{\mathrm{REF}}$ at several sites. This uncorrelated seasonal variation can be explained by identical errors derived from each transport model, systematic errors derived from the trilinear interpolation used to remap the data onto GECM coordinates, and the daily filter applied to sample concentrations at 13:00 local time. On the other hand, it was difficult to compare vertical $\mathrm{CO}_{2}^{\mathrm{GECM}}$ profiles with accurate in situ climatological profiles over the observation stations in the free troposphere. The vertical location of the known grid for aircraft measurements (green symbols in Figure 2a), from which the vertical coordinates of the GLOBALVIEW data set are specified in $1000 \mathrm{~m}$ intervals, differs from the true sampling locations. In the other interpolation grids, a strict evaluation of the seasonal variation in $\mathrm{CO}_{2}^{\mathrm{GECM}}$ is also not possible because there are weak observational constraints on the derived $\mathrm{CO}_{2}$ surface flux.

[29] In Figure 6, time series of total column in $\mathrm{X}_{\mathrm{CO} 2}^{\mathrm{GECM}}$ (red lines) and $\mathrm{X}_{\mathrm{CO} 2}^{\mathrm{ECM}}$ (blue lines) were compared to the event measurements by the Total Carbon Column Observing Network (TCCON) [Wunch et al., 2011] (black dots). An offset of $\mathrm{X}_{\mathrm{CO} 2}^{\mathrm{ECM}}$ has been manually adjusted by the annual mean concentration at South Pole. Differences in interhemispheric gradients among the transport models led to the increase in variance toward the northern latitudes. Also their biases were corrected by $\sim 1 \mathrm{ppm}$ from a comparison between $\mathrm{X}_{\mathrm{CO} 2}^{\mathrm{GECM}}$ and $\mathrm{X}_{\mathrm{CO} 2}^{\mathrm{ECM}}$. This bias correction was minimal at Darwin (Figure 6e), because it is located in the tropical latitude, where the stratospheric bias correction is small (red line in Figure 2b; detailed in the subsection 4.4 and Figure 7). Biases in $\mathrm{X}_{\mathrm{CO} 2}^{\mathrm{GECM}}$ were less than $0.56 \mathrm{ppm}$, except in Bialystok (Figure 6a) where $\mathrm{X}_{\mathrm{CO} 2}^{\mathrm{GECM}}$ was overestimated by $\sim 1.57 \mathrm{ppm}$. Recently, Butz et al. [2011] also reported that $\mathrm{X}_{\mathrm{CO} 2}$ from satellite measurements at Bialystok was larger by $\sim 1-2 \mathrm{ppm}$ than the other TCCON sites. Both the $\mathrm{X}_{\mathrm{CO} 2}^{\mathrm{ECM}}$ and $\mathrm{X}_{\mathrm{CO} 2}^{\mathrm{GECM}}$ time series produced high correlation coefficients (range $0.7=0.9$ ) with the TCCON data. The trough in seasonal cycles during the boreal summer, $\mathrm{X}_{\mathrm{CO} 2}^{\mathrm{GECM}}$ 
(a) Monthly $\mathrm{X}_{\mathrm{CO} 2}$ GECM in Jan 2009

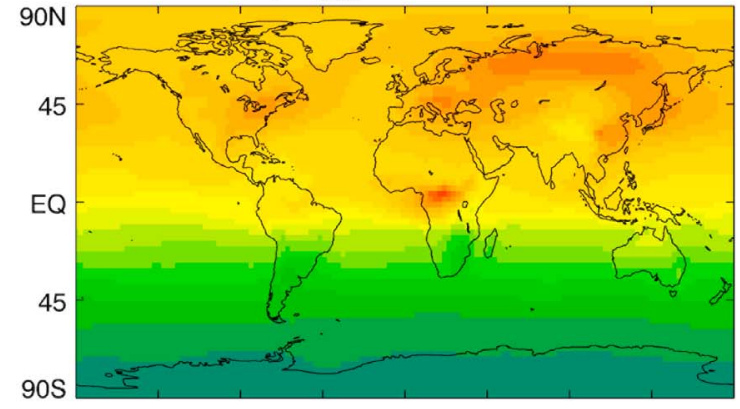

(c) Monthly $\mathrm{X}_{\mathrm{CO} 2}$ GECM in Apr 2009

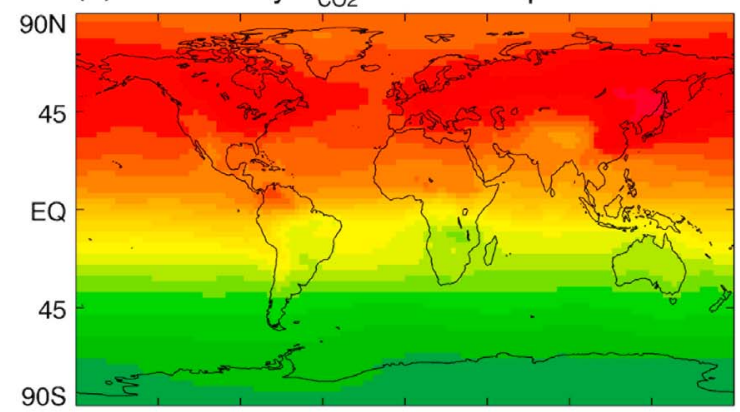

(e) Monthly $\mathrm{X}_{\mathrm{CO} 2}$ GECM in Jul 2009
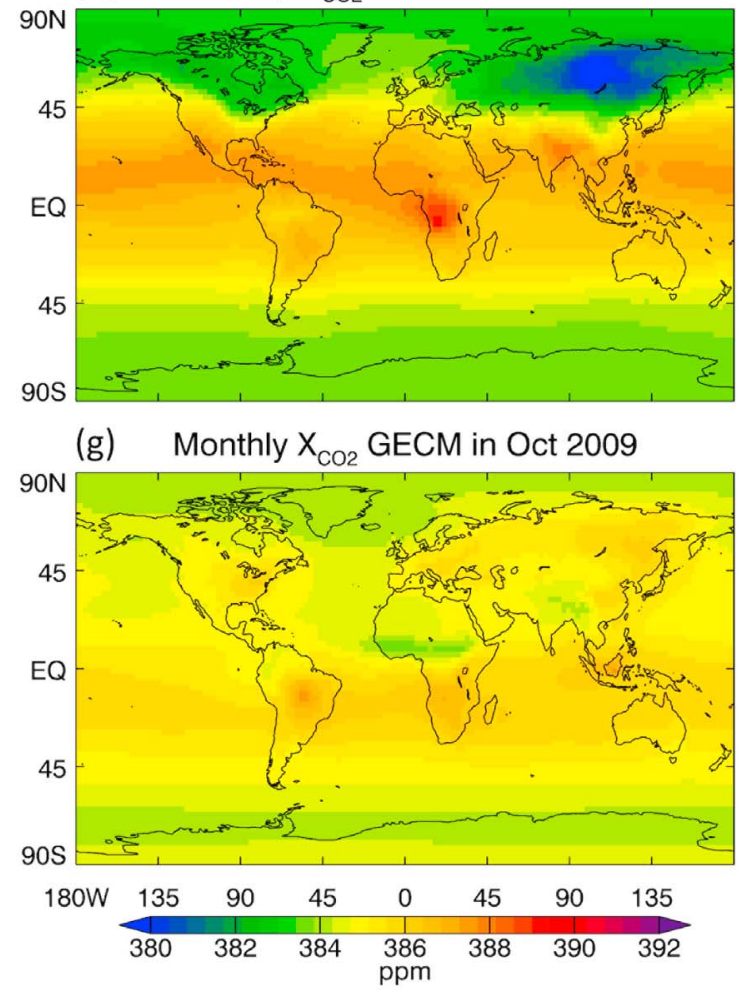

(b) Difference of GECM-ECM in Jan 2009

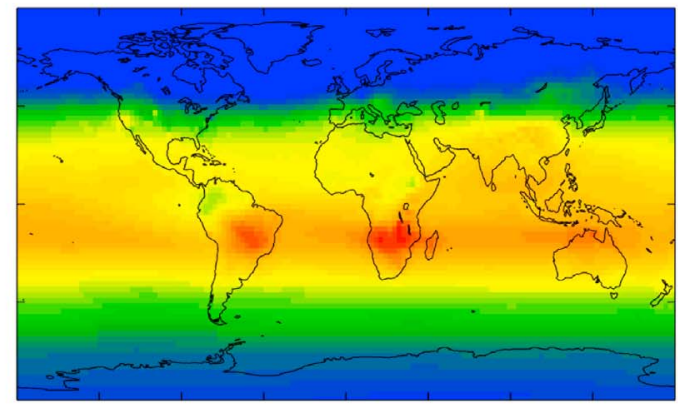

(d) Difference of GECM-ECM in Apr 2009

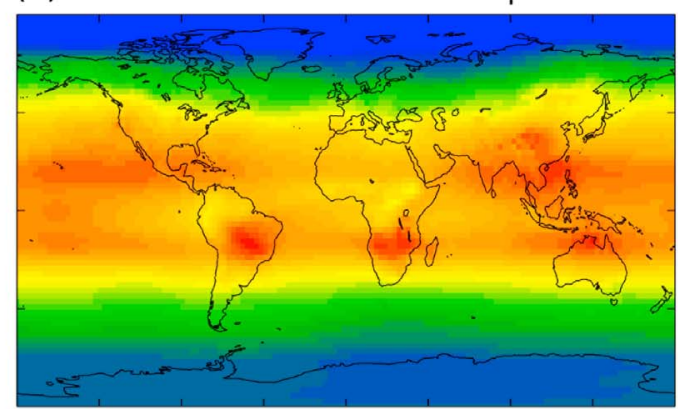

(f) Difference of GECM-ECM in Jul 2009

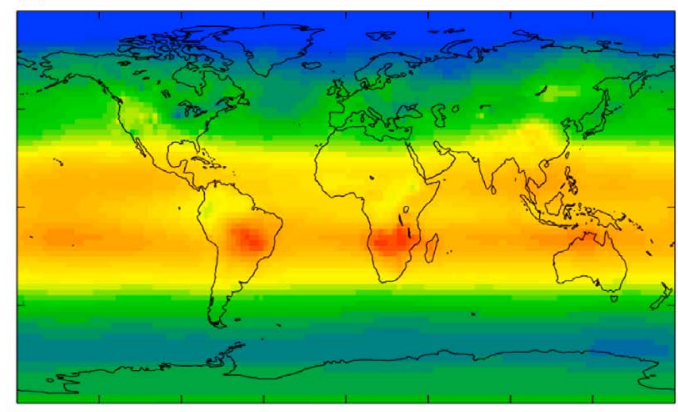

(h) Difference of GECM-ECM in Oct 2009

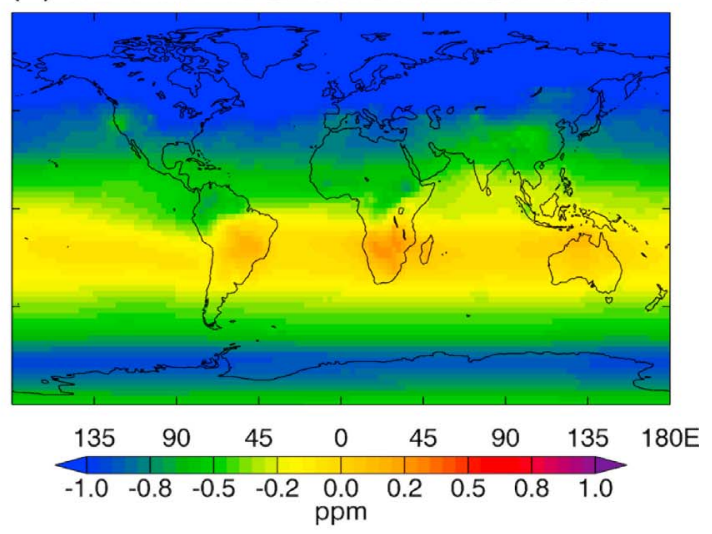

Figure 8. Monthly mean $\mathrm{X}_{\mathrm{CO} 2}$ concentrations in (a and b) January, (c and d) April, (e and f) June, and ( $\mathrm{g}$ and $\mathrm{h}$ ) October 2009 of GECM (Figures 8a, 8c, 8e, and 8g) and a difference (Figures 8b, 8d, 8f, and 8h) of GECM minus ECM. The GECM day-to-day variation in 2009 is shown in the auxiliary material.

was closer to the TCCON data than $\mathrm{X}_{\mathrm{CO} 2}^{\mathrm{ECM}}$ at the northern hemispheric sites. A more detailed analysis for seasonal cycles as simulated by the transport models and observed by the TCCON has been performed by Basu et al. [2011].

\subsection{Stratospheric Profiles}

[30] We have compared stratospheric $\mathrm{CO}_{2}^{\mathrm{GECM}}$ and $\mathrm{CO}_{2}^{\mathrm{ECM}}$ to assess the performance of the time-lag assumption that was defined as the vertical and latitudinal distribution of the 
seasonally varying age of air (Subsection 3.3). Figure 7 shows profiles of annual zonal mean $\mathrm{CO}_{2}^{\mathrm{GECM}}$ (open circles) and $\mathrm{CO}_{2}^{\mathrm{ECM}}$ ('plus' symbols) at northern midlatitudes $\left(35^{\circ} \mathrm{N}-45^{\circ} \mathrm{N}\right)$ (panel a) and tropical latitudes $\left(10^{\circ} \mathrm{S}-10^{\circ} \mathrm{N}\right)$ (panel b) in 2009, indicating how the time lag assumption shifts the $\mathrm{CO}_{2}^{\mathrm{GECM}}$ from $\mathrm{CO}_{2}^{\mathrm{ECM}}$ at the different latitudes. Vertical decrease ratios of $\mathrm{CO}_{2}^{\mathrm{GECM}}$ and $\mathrm{CO}_{2}^{\mathrm{ECM}}$ are clearly different in the vertical $\sigma$ range above $0.1\left(35^{\circ} \mathrm{N}-45^{\circ} \mathrm{N}\right)$ and $0.05\left(10^{\circ} \mathrm{S}-10^{\circ} \mathrm{N}\right)$. The column mean $\mathrm{CO}_{2}^{\mathrm{GECM}}\left(\mathrm{X}_{\mathrm{CO} 2}^{\mathrm{GEC}}\right)$ has become $\sim 384.1 \mathrm{ppm}\left(35^{\circ} \mathrm{N}-45^{\circ} \mathrm{N}\right)$ and $\sim 385.2 \mathrm{ppm}\left(10^{\circ} \mathrm{S}-\right.$ $10^{\circ} \mathrm{N}$ ) compared with $\mathrm{X}_{\mathrm{CO} 2}^{\mathrm{ECM}}$ of $\sim 384.7 \mathrm{ppm}$ and $\sim 385.0 \mathrm{ppm}$, respectively. Thus stratospheric bias corrections with the mean age of air has lowered the column concentration by $\sim 0.6 \mathrm{ppm}$ at midlatitudes and $\sim 0.2 \mathrm{ppm}$ at tropics, which is a reasonable conclusion to the estimation of interpolated bias shown in Figure $2 \mathrm{~b}$.

[31] In situ $\mathrm{CO}_{2}$ measurements in the stratosphere are important evaluation tools of the stratospheric bias correction. The observed mean age of air at $\sigma=0.01$ [Engel et al., 2009] is $\sim 5.5-6.0$ years at $35^{\circ} \mathrm{N}-45^{\circ} \mathrm{N}$, where therefore $\mathrm{CO}_{2}$ concentration in 2009 can be assumed to correspond to the annual mean concentration at the tropopause in 2003 $(\sim 375 \mathrm{ppm})$. In fact, the annual mean $\mathrm{CO}_{2}^{\mathrm{GECM}}$ in 2009 is also $\sim 375 \mathrm{ppm}$ as shown in Figure 7a. In situ stratospheric $\mathrm{CO}_{2}$ profiles [Engel et al., 2009] show a decrease of $6.7 \pm$ $1.5 \mathrm{ppm}$ from $15 \mathrm{~km}(\sigma=\sim 0.1)$ to $30 \mathrm{~km}(\sigma=\sim 0.01)$, where the corresponding $\mathrm{CO}_{2}^{\mathrm{GECM}}$ concentration difference amounted to $7.2 \pm 0.8 \mathrm{ppm}$. In another area where detailed validation of GECM performance is limited by the availability of measurement data, the latitudinal and vertical distribution of the mean age of air [Patra et al., 2009] played an important role correcting the vertical propagation of stratospheric $\mathrm{CO}_{2}^{\mathrm{GECM}}$.

\subsection{Global $\mathrm{X}_{\mathrm{CO} 2}$ in GECM and $\mathrm{ECM}$}

[32] Figure 8 shows the global $\mathrm{X}_{\mathrm{CO} 2}$ distribution in GECM (left panels) and the difference with ECM ( $\mathrm{X}_{\mathrm{CO} 2}^{\mathrm{GECM}}$ minus $\mathrm{X}_{\mathrm{CO} 2}^{\mathrm{ECM}}$ ) (Figure 8, right) (see also auxiliary material). ${ }^{1}$ $\mathrm{X}_{\mathrm{CO} 2}^{\mathrm{GEM}}$ on the subcontinents appear to have been weakly influenced by the regional bias correction, compared to the interpolated bias near the surface in Figure 2a. The significant land-ocean difference near the surface, caused by the regional bias correction (Figure 2a), almost blended into zonally corrected bias distributions in the stratosphere (right panels in Figure 8). The South Africa and Brazil regions always show positive differences every season. The positive in the Brazil region depends on our interpolation method around the site ABP. $\mathrm{CO}_{2}^{\mathrm{REF}}$ for $\mathrm{ABP}$ has been calculated from the fitting procedure based on only 2 -year records (2008-2009). Thus the 2-year based $\mathrm{CO}_{2}^{\mathrm{REF}}$ at $\mathrm{ABP}$ might be larger than a decadal-based $\mathrm{CO}_{2}^{\mathrm{REF}}$ at the other sites, reflected by higher growth rates for recent periods than past decades. Therefore, the bias correction in that area was possibly overestimated.

[33] The stratospheric bias correction mainly improved zonal $\mathrm{X}_{\mathrm{CO} 2}$ variations. $\mathrm{X}_{\mathrm{CO} 2}^{\mathrm{GEC}}$ at high latitudes in both hemispheres was reduced by $\sim 1 \mathrm{ppm}$ compared with $\mathrm{X}_{\mathrm{CO} 2}^{\mathrm{ECM}}$, whereas $\mathrm{X}_{\mathrm{CO} 2}^{\mathrm{GECM}}$ in mid-low latitudes was corrected by a

\footnotetext{
${ }^{1}$ Auxiliary materials are available in the HTML. doi:10.1029/ 2011JD016033.
}

positive bias less than $0.5 \mathrm{ppm}$. Considering data for all months, the annual mean of these differences (red line in Figure $2 b$ ) was close to zero ppm over the zonal tropic band.

\section{Conclusions}

[34] We have constructed a 3-D $\mathrm{CO}_{2}$ climatology (GECM). The seasonally varying climatology in GECM was estimated by an ensemble of the several transport models in combination with interpolated bias correction, using a data product based on in situ measurements in troposphere [GLOBALVIEW-CO2, 2010] and the monthly vertical and latitudinal distribution of the ACTM-derived mean age of air in the stratosphere. Six transport models participated in this study (Table 1). Model-to-model similarity in the climatology was shown via a multicomparison test of the six transport modeling results (Table 2). The seasonal cycles in $\mathrm{CO}_{2}$ derived from the transport models were strongly correlated with each other, except for Amazon and Central Africa where their standard error was relatively larger than for the other regions (Figure 3a).

[35] The interpolation methods employed in the troposphere were inverse distance weighting (IDW) and natural neighbor interpolation (NNI). At the coordinates of GLOBALVIEW sites, the $\mathrm{CO}_{2}$ concentration field of GECM $\left(\mathrm{CO}_{2}^{\mathrm{GECM}}\right)$ was equivalent to the in situ-based $\mathrm{CO}_{2}$ climatology $\left(\mathrm{CO}_{2}^{\mathrm{REF}}\right)$, following the IDW definition (Figure 5). Elsewhere, $\mathrm{CO}_{2}^{\mathrm{GECM}}$ was estimated by interpolating the bias between the average model and measurements. Having reduced the degree of misfit by interpolation, seasonal cycles were accurate over land and ocean, except for some regions with a low-density measurement network (Amazon and Central Africa). The regional horizontal pattern of $\mathrm{CO}_{2}^{\mathrm{GECM}}$ near the surface was optimized by the minimum variance method. As a result of the optimization, the global pattern of corrected bias was modified by $0.5 \mathrm{ppm}$ near the surface, whereas the bias correction modified the surface seasonal amplitude by several parts per million in tropical areas (Figure 4). In these tropical forest regions, a standard error among seasonal cycles of the transport models was larger $(>0.5 \mathrm{ppm})$ than the other subcontinents $(<0.2 \mathrm{ppm})$ shown in Figure 3. Regions on deserts and oceans had very small errors because of few $\mathrm{CO}_{2}$ sources and sinks from no vegetation. GECM reduced the model-tomodel errors by $40 \%$ (Figure 3c), especially in the Amazon, Siberia, and Central Africa, where Delaunay triangles are large, reflecting the scarcity of observation sites. In such areas, the exact solution of the minimum variance method would not be assured without in situ observations. In addition, the optimal solution for other parameters of the NNI and IDW interpolations could not be evaluated without true atmospheric $\mathrm{CO}_{2}$ concentrations. By the minimum variance method, not only linearly corrected seasonal cycles from IDW and NNI but also regionally varying those were applied for the surface bias corrections in GECM.

[36] The stratospheric bias was improved by the monthly vertical and latitudinal distribution of the mean age of air. A time-lag assumption was applied to the stratospheric altitudes to account for the underestimated age of air in the transport models, evaluated by the degree of agreement with in situ $\mathrm{CO}_{2}$ profiles in northern midlatitudes. The stratospheric bias correction decreased column mean $\mathrm{CO}_{2}$ 
concentrations by $\sim 1$ ppm near the poles (Figure 8 , right), $\sim 0.5 \mathrm{ppm}$ near midlatitudes (Figure $7 \mathrm{a}$ ), and less than $0.2 \mathrm{ppm}$ near the tropics (Figure $7 \mathrm{~b}$ ). This nonuniform bias with latitudes and regions (Figure 8, right) might have significant implications for evaluations of global satellite data products. Use of the corrected column should be incorporated in remote sensing retrieval algorithms and modeled $\mathrm{X}_{\mathrm{CO} 2}$ for surface flux estimations.

[37] Acknowledgments. This study is funded by the JSPS/MEXT KAKENHI-A (22241008), and the GOSAT joint project team of the National Institute for Environmental Studies (NIES), the Japan Aerospace Exploration Agency (JAXA) and the Ministry of the Environment (MOE). We wish to acknowledge those who contributed in making of the GLOBALVIEW-CO2 data set product. M. Satoh (University of Tokyo and JAMSTEC), H. Tomita (RIKEN and JAMSTEC) and other contributors are acknowledged for their work on the NICAM developments. M. Saito is acknowledged for his constructive comments on the terrestrial biome categories. CarbonTracker 2008 results are provided by the NOAA ESRL (Boulder, CO), made available at http://carbontracker.noaa.gov. TCCON data were obtained from the TCCON Data Archive, operated by the California Institute of Technology from the Website at http://tccon.ipac.caltech.edu/.

\section{References}

Araki, M., I. Morino, T. Machida, Y. Sawa, H. Matsueda, H. Ohyama, T. Yokota, and O. Uchino (2010), $\mathrm{CO}_{2}$ column-averaged volume mixing ratio derived over Tsukuba from measurements by commercial airlines, Atmos. Chem. Phys., 10, 7659-7667, doi:10.5194/acp-10-7659-2010.

Baker, D. F., et al. (2006), TransCom 3 inversion intercomparison: Impact of transport model errors on the interannual variability of regional $\mathrm{CO}_{2}$ fluxes, 1988-2003, Global Biogeochem. Cycles, 20, GB1002, doi:10.1029/ 2004GB002439.

Basu, S., S. Houweling, W. Peters, C. Sweeney, T. Machisa, S. Maksyutov, P. K. Patra, R. Saito, F. Chevallier, Y. Niwa, H. Matsueda, and Y. Sawa (2011), The seasonal cycle amplitude of total column $\mathrm{CO}_{2}$ : Factors behind the model-observation mismatch, J. Geophys. Res., doi:10.1029/ 2011JD016124, in press.

Belikov, D., S. Maksyutov, T. Miyasaka, T. Saeki, R. Zhuravlev, and B. Kiryushov (2011), Mass-conserving tracer transport modeling on a reduced latitude-longitude grid with NIES-TM, Geosci. Model Dev., 4, 207-222, doi:10.5194/gmd-4-207-2011.

Butz, A., et al. (2011), Toward accurate $\mathrm{CO}_{2}$ and $\mathrm{CH}_{4}$ observations from GOSAT, Geophys. Res. Lett., 38, L14812, doi:10.1029/2011GL047888.

Chevallier, F., M. Fisher, P. Peylin, S. Serrar, P. Bousquet, F.-M. Bréon, A. Chédin, and P. Ciais (2005), Inferring $\mathrm{CO}_{2}$ sources and sinks from satellite observations: Method and application to TOVS data, J. Geophys. Res., 110, D24309, doi:10.1029/2005JD006390.

Chevallier, F., F. Bréon, and P. J. Rayner (2007), Contribution of the Orbiting Carbon Observatory to the estimation of $\mathrm{CO}_{2}$ sources and sinks: Theoretical study in a variational data assimilation framework, J. Geophys. Res., 112, D09307, doi:10.1029/2006JD007375.

Chevallier, F., S. Maksyutov, P. Bousquet, F.-M. Bréon, R. Saito, Y. Yoshida, and T. Yokota (2009), On the accuracy of the $\mathrm{CO}_{2}$ surface fluxes to be estimated from the GOSAT observations, Geophys. Res. Lett., 36, L19807, doi:10.1029/2009GL040108.

Eguchi, N., R. Saito, T. Saeki, Y. Nakatsuka, D. Belikov, and S. Maksyutov (2010), A priori covariance estimation for $\mathrm{CO}_{2}$ and $\mathrm{CH}_{4}$ retrievals, J. Geophys. Res., 115, D10215, doi:10.1029/2009JD013269.

Engel, A., et al. (2009), Age of stratospheric air unchanged within uncertainties over the past 30 years, Nat. Geosci., 2, 28-31, doi:10.1038/ngeo388.

Engelen, R. J., S. Serrar, and F. Chevallier (2009), Four-dimensional data assimilation of atmospheric $\mathrm{CO}_{2}$ using AIRS observations, J. Geophys. Res., 114, D03303, doi:10.1029/2008JD010739.

Feng, L., P. I. Palmer, H. Bösch, and S. Dance (2009), Estimating surface $\mathrm{CO}_{2}$ fluxes from space-borne $\mathrm{CO}_{2}$ dry air mole fraction observations using an ensemble Kalman Filter, Atmos. Chem. Phys., 9, 2619-2633, doi:10.5194/acp-9-2619-2009.

Friedl, M. A., et al. (2002), Global land cover mapping from MODIS: Algorithms and early results, Remote Sens. Environ., 83, 287-302, doi:10.1016/S0034-4257(02)00078-0.

GLOBALVIEW-CO2 (2010), Cooperative Atmospheric Data Integration Project - Carbon Dioxide [CD-ROM], NOAA ESRL, Boulder, Colo. [Available via anonymous FTP to ftp.cmdl.noaa.gov, Path: $\mathrm{Ccg} / \mathrm{co} 2 /$ GLOBALVIEW.]
Gurney, K., R. Law, P. Rayner, and A. S. Denning (2004), Transcom 3 inversion intercomparison: Model mean results for the estimation of seasonal carbon sources and sinks, Global Biogeochem. Cycles, 18, GB1010, doi:10.1029/2003GB002111.

Harnisch, J., R. Borchers, P. Fabian, and M. Maiss (1996), Tropospheric trends for $\mathrm{CF}_{4}$ and $\mathrm{C}_{2} \mathrm{~F}_{6}$ since 1982 derived from $\mathrm{SF}_{6}$ dated stratospheric air, Geophys. Res. Lett., 23, 1099-1102, doi:10.1029/96GL01198.

Hourdin, F., et al. (2006), The LMDZ4 general circulation model: Climate performance and sensitivity to parametrized physics with emphasis on tropical convection, Clim. Dyn., 27, 787-813, doi:10.1007/s00382-0060158-0.

Houweling, S., F.-M. Bréon, I. Aben, C. Rodenbeck, M. Gloor, M. Heimann, and P. Ciais (2004), Inverse modeling of $\mathrm{CO}_{2}$ sources and sinks using satellite data: A synthetic inter-comparison of measurement techniques and their performance as a function of space and time, Atmos. Chem. Phys., 4, 523-538, doi:10.5194/acp-4-523-2004.

Jiang, X., M. T. Chahine, E. T. Olsen, L. L. Chen, and Y. L. Yung (2010), Interannual variability of midtropospheric $\mathrm{CO}_{2}$ from Atmospheric Infrared Sounder, Geophys. Res. Lett., 37, L13801, doi:10.1029/2010GL042823.

Kawa, S. R., D. J. Erickson III, S. Pawson, and Z. Zhu (2004), Global CO transport simulations using meteorological data from the NASA data assimilation system, J. Geophys. Res., 109, D18312, doi:10.1029/ 2004JD004554.

Krol, M., S. Houweling, B. Bregman, M. van den Broek, A. Segers, P. van Velthoven, W. Peters, F. Dentener, and P. Bergamaschi (2005), The two-way nested global chemistry-transport zoom model TM5: Algorithm and applications, Atmos. Chem. Phys., 5, 417-432, doi:10.5194/ acp-5-417-2005.

Law, R. M., et al. (2008), TransCom model simulations of hourly atmospheric $\mathrm{CO}_{2}$ : Experimental overview and diurnal cycle results for 2002, Global Biogeochem. Cycles, 22, GB3009, doi:10.1029/2007GB003050.

Maksyutov, S., P. K. Patra, R. Onishi, T. Saeki, and T. Nakazawa (2008), NIES/FRCGC global atmospheric tracer transport model: Description, validation, and surface sources and sinks inversion, J. Earth Simulator, 9, 3-18.

Masarie, K. A., and P. P. Tans (1995), Extension and integration of atmospheric carbon dioxide data into a globally consistent measurement record, J. Geophys. Res., 100, 11,593-11,610, doi:10.1029/95JD00859.

Miura, H. (2007), An upwind-biased conservative advection scheme for spherical hexagonal-pentagonal grids, Mon. Weather Rev., 135, 4038-4044, doi:10.1175/2007MWR2101.1.

Niwa, Y., H. Tomita, M. Satoh, and R. Imasu (2011), A three-dimensional icosahedral grid advection scheme preserving monotonicity and consistency with continuity for atmospheric tracer transport, J. Meteorol. Soc. Jpn., 89, 255-268, doi:10.2151/jmsj.2011-306.

Olivier, J. G. J., and J. J. M. Berdowski (2001), Global emissions sources and sinks, in The Climate System, edited by J. Berdowski, R. Guicherit, and B. J. Heij, pp. 33-78, A. A. Balkema, Lisse, Netherlands.

Olsen, S. C., and J. T. Randerson (2004), Differences between surface and column atmospheric $\mathrm{CO}_{2}$ and implications for carbon cycle research, J. Geophys. Res., 109, D02301, doi:10.1029/2003JD003968.

Patra, P. K., S. Lal, B. H. Subbaraya, C. H. Jackman, and P. Rajaratnam (1997), Observed vertical profile of sulphur hexafluoride $\left(\mathrm{SF}_{6}\right)$ and its atmospheric applications, J. Geophys. Res., 102, 8855-8859, doi:10.1029/ 96JD03503.

Patra, P. K., S. Maksyutov, Y. Sasano, H. Nakajima, G. Inoue, and T. Nakazawa (2003), An evaluation of $\mathrm{CO}_{2}$ observations with Solar Occultation FTS for Inclined-Orbit Satellite sensor for surface source inversion, J. Geophys. Res., 108(D24), 4759, doi:10.1029/2003JD003661.

Patra, P. K., et al. (2008), TransCom model simulations of hourly atmospheric $\mathrm{CO}_{2}$ : Analysis of synoptic-scale variations for the period 2002-2003, Global Biogeochem. Cycles, 22, GB4013, doi:10.1029/ 2007 GB003081.

Patra, P. K., M. Takigawa, G. S. Dutton, K. Uhse, K. Ishijima, B. R. Lintner, K. Miyazaki, and J. W. Elkins (2009), Transport mechanisms for synoptic, seasonal and interannual $\mathrm{SF}_{6}$ variations and 'age' of air in troposphere, Atmos. Chem. Phys., 9, 1209-1225, doi:10.5194/acp-9-1209-2009.

Pérez-Landa, G., P. Ciais, G. Gangoiti, J. L. Palau, A. Carrara, B. Gioli, F. Miglietta, M. Schumacher, M. M. Millán, and M. J. Sanz (2007), Mesoscale circulations over complex terrain in the Valencia coastal region, Spain-Part 2: Modeling $\mathrm{CO}_{2}$ transport using idealized surface fluxes, Atmos. Chem. Phys., 7, 1851-1868, doi:10.5194/acp-7-1851-2007.

Peters, W., et al. (2007), An atmospheric perspective on North American carbon dioxide exchange: CarbonTracker, Proc. Natl. Acad. Sci. U. S. A., 104(48), 18,925-18,930, doi:10.1073/pnas.0708986104.

Rayner, P. J., and D. M. O'Brien (2001), The utility of remotely sensed $\mathrm{CO}_{2}$ concentration data in surface inversion, Geophys. Res. Lett., 28, 175-178, doi:10.1029/2000GL011912. 
Satoh, M., T. Matsuno, H. Tomita, H. Miura, T. Nasuno, and S. Iga (2008), Nonhydrostatic Icosahedral Atmospheric Model (NICAM) for global cloud resolving simulations, J. Comput. Phys., 227, 3486-3514.

Schneising, O., M. Buchwitz, M. Reuter, J. Heymann, H. Bovensmann, and J. P. Burrows (2011), Long-term analysis of carbon dioxide and methane column-averaged mole fractions retrieved from SCIAMACHY, Atmos. Chem. Phys., 11, 2863-2880, doi:10.5194/acp-11-2863-2011.

Takahashi, T., et al. (2002), Global sea-air $\mathrm{CO}_{2}$ flux based on climatological surface ocean $\mathrm{pCO}_{2}$, and seasonal biological and temperature effects, Deep Sea Res., Part II, 49, 1601-1622, doi:10.1016/S0967-0645(02) 00003-6.

van der Werf, G. R., J. T. Randerson, L. Giglio, G. J. Collatz, P. S. Kasibhatla, and A. F. Arellano Jr. (2006), Interannual variability in global biomass burning emissions from 1997 to 2004, Atmos. Chem. Phys., 6, 3423-3441, doi:10.5194/acp-6-3423-2006.

Watson, D. F. (1992), Contouring: A Guide to the Analysis and Display of Spatial Data, Pergamon, New York.

Wunch, D., G. C. Toon, J.-F. L. Blavier, R. A. Washenfelder, J. Notholt, B. J. Connor, D. W. T. Griffith, V. Sherlock, and P. O. Wennberg (2011), The Total Carbon Column Observing Network, Philos. Trans. R. Soc. A, 369, 2087-2112, doi:10.1098/rsta.2010.0240.
Yoshida, Y., Y. Ota, N. Eguchi, N. Kikuchi, K. Nobuta, H. Tran, I. Morino, and T. Yokota (2011), Retrieval algorithm for $\mathrm{CO}_{2}$ and $\mathrm{CH}_{4}$ column abundances from short-wavelength infrared spectral observations by the Greenhouse gases observing satellite, Atmos. Meas. Tech., 4, 717-734, doi:10.5194/amt-4-717-2011.

D. Belikov, S. Maksyutov, and T. Saeki, Center for Global Environmental Research, National Institute for Environmental Studies, 16-2 Onogawa, Tsukuba, Ibaraki 305-8506, Japan.

F. Chevallier, Laboratoire des Sciences du Climat et de l'Environnement, CEA-CNRS-UVSQ/IPSL, bat 701, L' Orme des Merisiers, F-91191 Gif-surYvette, France.

A. Houweling, SRON Netherlands Institute for Space Research, NL-3584 CA Utrecht, Netherlands.

R. Lokupitiya, Department of Atmospheric Science, Colorado State University, Fort Collins, CO 80523, USA.

Y. Niwa, Meteorological Research Institute, Tsukuba, Ibaraki 305-0052, Japan.

P. K. Patra and R. Saito, Research Institute for Global Change, JAMSTEC, 3173-25 Showa-machi, Yokohama, Kanagawa 236-0001, Japan. (rsaito@jamstec.go.jp) 